\title{
The effects of nano- and micro-sized additives on 3D printable cementitious and alkali-activated composites: a review
}

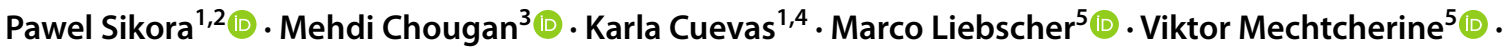

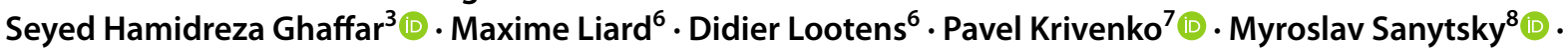 \\ Dietmar Stephan ${ }^{1}$ (i)
}

Received: 30 November 2020 / Accepted: 12 February 2021 / Published online: 27 February 2021

(c) The Author(s) 2021

\begin{abstract}
Additive manufacturing (AM), also referred as 3D printing, is a technology that enables building automated three-dimensional objects in a layer-by-layer manner. AM of cement-based and alkali-activated composites has gathered attention over the last decade and is one of the most rapidly developing civil engineering fields. Development of proper mixture compositions which are suitable in fresh and hardened state is one of the key challenges of AM technology in construction. As the behaviour of cement-based materials (CBM) and alkali-activated materials (AAM) is determined by chemical and physical processes at the nano-level, incorporation of nano- and micro-sized admixtures has great influence on the performance of printable composites. These modifications are attributed to the unique reactivity of nanoparticles associated with their small size and large surface area. This review paper summarizes recent developments in the application of nano- and micro-particles on 3D printable cementitious composites and how they influence the performance of 3D-printed construction materials. The research progress on nano-engineered CBM and AAM is reviewed from the view of fresh and hardened properties. Moreover, comparison between nano- and micro-sized admixtures including nanosilica, graphene-based materials, and clay nanoparticles as well as chemical admixtures such as viscosity-modifying admixtures and superplasticizers is presented. Finally, the existing problems in current research and future perspectives are summarized. This review provides useful recommendations toward the significant influence of nano- and micro-sized admixtures on the performance of 3D printable CBMs.
\end{abstract}

Keywords 3D printing $\cdot$ Additive manufacturing $\cdot$ Concrete $\cdot$ Cement $\cdot$ Alkali-activated materials $\cdot$ Nanomaterials . Admixtures

Submitted to the special issue of NANO-2020, within the 8th International Conference "Nanotechnologies and Nanomaterials" NANO-2020.

Pawel Sikora

pawel.sikora@zut.edu.pl

1 Building Materials and Construction Chemistry, Technische Universität Berlin, Gustav-Meyer-Allee 25, 13355 Berlin, Germany

2 Faculty of Civil and Environmental Engineering, West Pomeranian University of Technology Szczecin, Al. Piastow 50, Szczecin 70-311, Poland

3 Department of Civil and Environmental Engineering, Brunel University London, Uxbridge UB8 3PH, UK

4 Pontificia Universidad Catolica de Chile, Engineering School-DCEM, Vicuña Mackenna 4860, 7820436 Santiago, Chile
5 Institute of Construction Materials, TU Dresden, 01062 Dresden, Germany

6 Sika Technology AG-Central Research, Zurich, Switzerland

7 V. Glukhovsky Scientific Research Institute for Binders and Materials, Kyiv National University of Construction and Architecture, Povitroflotsky Ave., 31, Kyiv 03037, Ukraine

8 Lviv Polytechnic National University, S. Bandera Str. 12, Lviv 79013, Ukraine 


\section{Introduction}

The construction sector has one of the slowest automatization rates compared to other industries. Due to simplicity of the building techniques as well as low automatization level, civil engineering is a sector of the economy characterized by high volatility of working conditions, which are a source of many threats to the worker's life and health and contribute to high accident rates. Therefore, various methods including introduction of constructing systems or automatization are sought to speed-up the construction process as well as increase the safety of the workers.

Additive manufacturing (AM), also referred to as 3D printing, is a technology that enables building physical components of a three-dimensional object in a layer-by-layer manner. In recent years, it is one of the most rapidly developing fields in civil engineering and is considered one of the key pillars of the Industry 4.0 concept (Prinsloo et al. 2019). With AM, an innovative digital manufacturing technology is now available that enables freedom in concrete manufacturing with an efficient use of materials. There is a global need to increase production of homes and to achieve the required outputs, the industry needs to leverage technology more so than ever before. Much of this will be achieved through utilizing Modern Methods of Construction, i.e. 3D-printed pre-fabricated building blocks (Ghaffar and Mullett 2018; Ghaffar et al. 2018; Ghaffar et al. 2020).

$3 \mathrm{D}$ printing started being developed in the biomedical and industrial manufactory sector in the mid-1980s and adopted during the 1990s in the construction industry through the "Contour Crafting" and "Selective aggregation" printing methods to later develop in the twenty-first century "Freeform construction" or "Concrete Printing" technology (Khan et al. 2020). Among digital fabrication methods: extrusion, formwork printing, temporary supports, slip-forming and particle bed fusion techniques can be distinguished (Wangler et al. 2019). Figure 1 shows the rise in AM for construction between the years 1997 and 2018, showing that the tendency and complexity of 3D-printed designs continuous to increase throughout the years.

AM technology has a manifold of benefits, when compared to conventional concrete construction projects. First, this technology offers new structural possibilities, which cannot be achieved with a conventional construction process (Pacewicz et al. 2018; Hoffmann et al. 2020). Due to unprecedented architectural freedom, advanced structures without increasing the costs or decreasing productivity due to the complexity of the design can be produced (Labonnote and Rüther 2017). In addition, since 3D printing is formwork-free and because project times are short due to the continuous work of the printer and less labour force required, a dramatic reduction in project costs can be

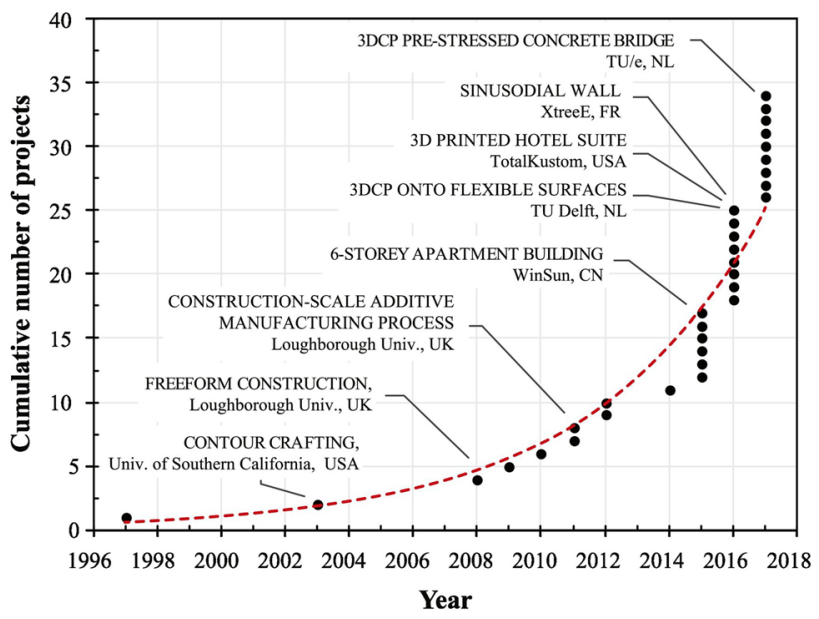

Fig. 1 The rise in large-scale additive manufacturing for construction applications since the concept inception in 1997. Reprinted from Buswell et al. (2018)

achieved as a result (García de Soto et al. 2018; Paul et al. 2018; Valente et al. 2019). Moreover, 3D printing was found to reduce the construction wastes production (Zhang et al. 2019).

Although concrete printing technology has seen remarkable development in recent years, there is still a strong need to develop a proper 3D printing material with improved performance along with decreasing the material consumption, which is of high importance for the $\mathrm{CO}_{2}$ reduction (Rahul et al. 2019b). One of the materials which can significantly change the performance of 3D-printed composites are nanomaterials (NMs). As the behaviour of cement-based materials (CBM) and alkaliactivated (AAM) materials is influenced by chemical and physical processes at the nano-level, the incorporation of nanoparticles has remarkable effects on the performance of printable composites. These modifications are attributed to the nanoparticles' unique reactivity and physical effects associated with their small and large surface areas (Ma and Wang 2018; Krivenko et al. 2019). In the case of ordinary concretes, the majority of research attention has been paid to modification and evaluation of the hardened properties of cementitious composites. However, research related to the fresh properties of cementitious composites modified with NMs, indicates that these materials might be extremely suitable for 3D printing concrete (3DPC) applications. NMs enable the precise control of the fresh state characteristics of composites by modifying the rheological behaviour of materials (inducing the thixotropy behaviour), which are crucial for the composite printing process. Enhanced interlayer bonding, layers shape stability and thus the final properties of the composite are subsequently affected. The 
advantage of NMs over conventional admixtures lies in the fact that even a small amount of NMs have a spectacular impact on the properties of fresh blends. At early age, the cement paste behaves as a low concentration suspension with lubrication provided by the free water. As the hydration progresses, the points of contact between the particles increase along with decrement of available free water. This results in the reduction of the lubrication between particles provided by the water (Wang et al 2014). Selected NMs can act as the nucleation seeds for the hydration reaction of the cement, which results in earlier formation of hydration products (e.g. C-S-H), which increases the number of solid-solid contacts. This in turn affects the thixotropic properties of the mixture (Land and Stephan 2012; Sikora et al. 2020b). In contrary, when inert NMs are used, the effect of paste rheology is mainly attributed to the ultra-fine particle size and consequently, the competing effects between packing behaviour and interparticle forces (Wang et al. 2014). NMs could be viable solutions to be incorporated into 3DPC as the production costs of nanoparticles has been significantly decreased over years with commercially available products dedicated for construction industry (Charitidis et al. 2014; Jones et al. 2019; Ivanov et al. 2020).

Although the effects of NMs on the properties of conventional concretes are widely established, they cannot be directly transferred to materials used in AM technology, this is due to differences between the mixture composition of printable cementitious composite and conventional one. Therefore, there is a strong research need to understand the effects of nano- as well as micro-particles on the properties of printable mixtures. To date, many valuable review papers have been published (Buswell et al. 2018; Ma and Wang 2018; Hamidi and Aslani 2019; Lu et al. 2019; Valente et al. 2019; Wangler et al. 2019; Zhang et al. 2019; Mechtcherine et al. 2020); however, most of them deal with the topics of production steps, technological aspects of printing, testing methods, general mixture design requirements as well as underlying physics. To the best of author's knowledge, the latest state-of-art related to the potential of nanosized admixtures is not available in the literature.

The objective of this paper is therefore, to summarize recent developments in the application of nano- and microparticles on 3D printable cementitious composites and how they influence the performance of 3D-printed construction materials. The research progress on nano-engineered CBMs and AAMs is reviewed from the view of fresh and hardened properties. Moreover, comparison between nano- and microsized admixtures as well as chemical admixtures such as VMAs and SP is presented. Finally, the existing problems in current research future perspectives are presented.

\section{Basic principles of 3D-printed concrete}

Concrete used for 3D printing can be considered as a filament/ink material for 3D printed and has to fulfil certain requirements to be suitable for extrusion through a pipepump-nozzle system. Three different extrusion-based printing regimes have been proposed in the literature (Albar et al. 2020): (1) conventional extrusion in which the filament and nozzle have the same cross-section dimensions. This method is generally used for the printing of ultra-stiff materials. (2) Free-flow extrusion, which refers to the extrusion of flowable material without using external forces. In this method, the material flows freely from the nozzle using only gravity energy. It should be noted that material flows until the stress generated by the gravity and shear yield stress of the printable materials reaches the equilibrium state. (3) Utilization of non-equal filament/nozzle cross-section dimensions coupled with external input forces such as vibration, enables stiff materials to be printed and appropriately deposited. The non-equality of filament/nozzle size, i.e. lower dimension of nozzle comparing to the filament size, induces the shear localization of materials in the nozzle, leading to printing of fluctuated material (Roussel 2018; Mechtcherine et al. 2020). In addition, determination of the suitable mixture design using available high-quality cementitious materials is crucial when considering a mixture to be $3 \mathrm{D}$ printed, since due to overgoing cement hydration process concrete exhibits its fresh (plastic) properties up to a certain point afterwards the stiffening process occurs, which leads to hardening of the concrete. Since concrete has to be stable and withstand the subsequent layers being deposited, its mixture composition and fresh behaviour have to be different to that of conventional concrete.

\section{Fresh properties of 3D printable mixtures}

The qualitative descriptors of the 3D printable concrete are pumpability, extrudability, workability, open time and buildability.

Pumpability can be defined as the capacity of a concrete specimen to be mobilized under pressure meanwhile maintaining the initial properties (Jolin et al. 2009). The pumpability index is generally tested through the classical slump test and slump flow test (Khan 2020). In other studies, pumpability has been quantified through tribometer testing, a sliding pipe rheometer, and a viscometer (Mechtcherine et al. 2014; Secrieru et al. 2017). The results of these particular tests have to be culminated to fully understand the phenomena of pumpability.

Extrudability is the ability of concrete to be continuously printed through the nozzle (Malaeb et al. 2019) and has been measured with a ram extruder (Figueiredo et al. 2019), by

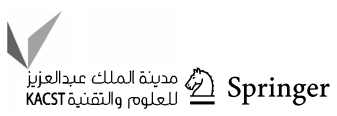


visual observation (Rahul et al. 2019a), through a $4.45 \mathrm{KN}$ servo-controlled MTS machine (Alghamdi et al. 2019) and using other unregulated tests for this property (Chen et al. 2020b). Visual observation can be an initial approach, yet it has a significant probability of human error. These tests have not proven to be the most precise and reliable alternatives to test extrudability in 3D-printed concrete (3DPC) without appropriate standards and guidelines.

To determine the workability of a mixture in 3D printing, open time is an important aspect to consider. Open time corresponds to the time the mix is dispensed through the nozzle without stopping or clogging (Jo et al. 2020). Workability in 3DPC has been tested through a rotational rheometer, Vicat method, and flow table (Papachristoforou et al. 2018). Papachristoforou et al. (2018) have remarked the inconsistency in the results of workability when using the Vicat method.

Buildability is the ability of the printed concrete layers to support the subsequent layers on top without buckling (Malaeb et al. 2019). For buildability, as there is not a standardized test procedure, research groups have presented various testing methods. Several consist of nonvalidated methods and are unrelated to experimental work. However, others reported contrasting testing conditions (Mechtcherine et al. 2020). Mechtcherine et al. (2020) reported the usage of ram extruders, triaxial compression tests, a rotational rheometer, and unconfined material compression to quantify buildability in 3DPC.

A concrete mix with high-static yield stress and lowdynamic yield stress of concrete is desired. The discrepancy between dynamic and static yield stress is related to thixotropy, thus the 3D printable concrete requires high thixotropic behaviour (Lu et al. 2019). Thixotropy is a time-dependent phenomenon and can be briefly characterized as fluidification of the material under (high) shear

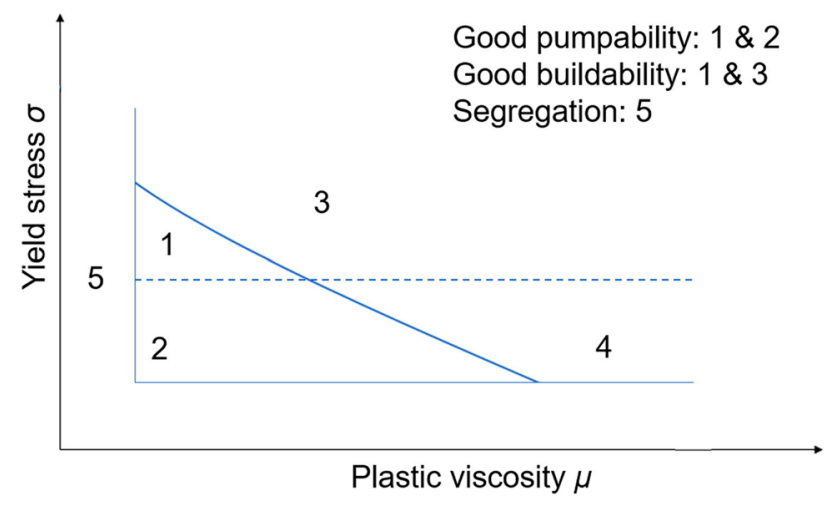

Fig. 2 Schematic diagram of the relationship between different combinations of yield stress and plastic viscosity in relation to concrete printing properties. Reprinted from Lu et al. (2019) with permission of Elsevier, 2019 and stiffening at rest (or at low shear rates) (Wallevik et al. 2015). In addition, shorter setting time and higher early strength to that of conventional concrete is required (Zhang et al. 2019). An example of desired properties towards theoretical good printing is presented in Fig. 2, where the optimum pumpability involves high-yield stress and a plastic viscosity on the lower side of the spectrum. It can also be observed that segregation in 3DPC is related to a very low plastic viscosity, therefore, there is a limit on the minimum value of plastic viscosity to achieve a stable 3D printable mixture.

\section{Hardened properties and microstructural characteristics}

Various final (hardened) properties such as layer adhesion, bulk density, mechanical properties, shrinkage and durability are the factors which should be taken into account when designing a mixture for 3D printing (Buswell et al. 2018). Most of these parameters are highly dependent on the mixture composition as well as the printing process.

Since 3D printable mixture requires high content of fine particles in the composition and hydration process is in open atmosphere due to the lack of formwork, moisture loss can occur, which could increase shrinkage and cracking of the structure (Wangler et al. 2019; Federowicz et al. 2020). These conditions where curing is not optimum can result in an increment of cracking in such mixtures, increasing the water penetration and aggressive chemicals, deteriorating the cement paste, and therefore, reducing the life span of the structure (Kaszynska and Zielinski 2015).

Among the microstructural characteristics, pore volume and distribution are essential to understand the behaviour of 3D printing concrete, especially in the interlayer bond, which has been characterized as one of the weakest sections in printed elements (Buswell et al. 2018; Nerella et al. 2019). Van der Putten et al. (2019) have reported that 3D-printed concrete possesses many flat and elongated pores, especially in the inter-layer transition zone. Similarly, Lee et al. (2019) have reported slightly increased porosity in the interlayer zones of 3D-printed specimens, although they did not find pore volume to be directly correlated with the tensile strength of specimens.

\section{Design formulations for 3D printable cementitious composites}

Various quantities of fine aggregates and chemical admixtures are required to produce concrete, depending on the strength category of concrete desired e.g. traditional concrete, ultra-high-performance concrete (UHPC) or 3D-printed concrete. An example of raw material proportions of traditional concrete, UHPC and 3D-printed concrete 


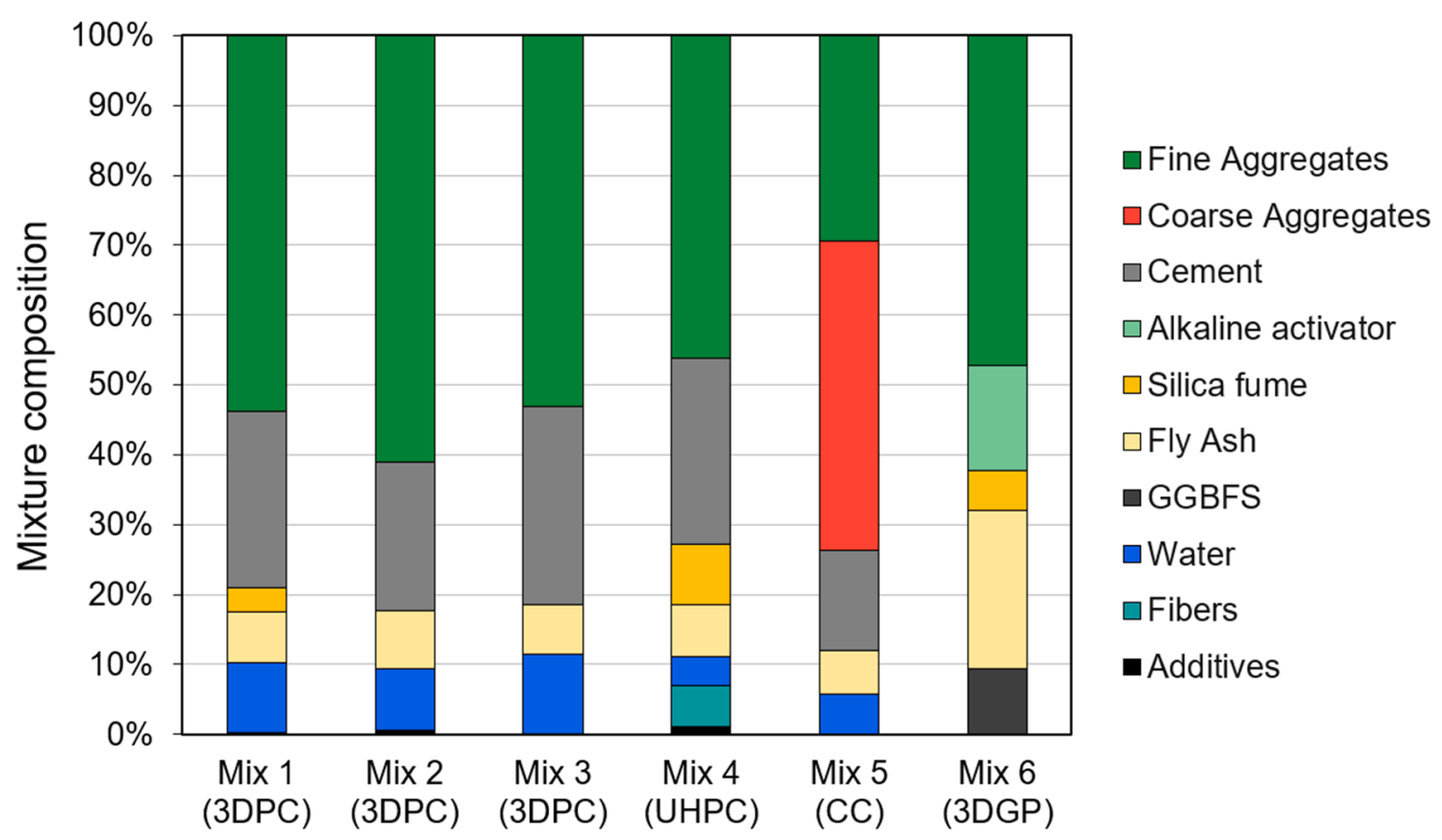

Fig. 3 Mixture composition in percentage of mass for conventional concrete (CC), ultra-high-performance concrete (UHPC), 3D-printed cement-based concretes (3DPC) and multi-binder geopolymer (3DGP)

mixtures is presented in Fig. 3. Three cement-based mixtures selected to be printed (3DPC): mixture 1 (Le et al. 2012b), mixture 2 (Nerella and Mechtcherine 2019) and mixture 3 (Rahul et al. 2019a) and one (mixture 6) multi-binder geopolymer (Chougan et al. 2020a) were analyzed. Mixture 4 (Graybeal 2006) is an UHPC and mixture 5 (Neville and Brooks 2010) is a traditional concrete mixture without any additives (CC). Widely used supplementary binders such as fly ash and silica fume were selected in the mixtures to compare representative specimens.

One of the most significant differences between 3DPC and conventional concrete is the addition of coarse aggregates on the traditional mixtures. Coarse aggregates are not printable in a general basis and not used or used in a small portion in UHPC. Studies have shown that the addition of coarse aggregate in the ratio of $0.33-1.00$ of coarse aggregate over fine aggregate reduces strength between 0 to $7 \%$ and the slump flow up to $55 \%$, affecting workability; although the addition of coarse aggregate in a ratio lower than 0.5 improves the economy of the mix as compressive strength and workability is not strongly affected (Sobuz et al. 2016).

Another significant difference between these categories of concrete is the amount of cement used. Conventional concrete is the one that utilizes less cement in the three categories mentioned and that has a lower binder percentage, as well as a lower amount of the fine aggregates and admixtures.
Additional binders and admixtures are commonly used in 3DPC to modify the thixotropy of the mixture, which improve the properties of extrudability, pumpability and buildability. Moreover, supplementary cementitious materials (SCMs) such as silica fume or limestone powder are used to modify the rheological properties of mixtures along with decreasing the cement content in the mixtures (Ma et al. 2018; Skibicki et al. 2020). Additionally, nanomaterials have gathered particular attention due to their unique physical properties as well as significant chemical reactivity, which is the result of their ultra-fine size and high-specific surface area (Sikora et al. 2018). As such, even a small dosage can substantially affect both the fresh and hardened properties of printable composites.

Depending on the type of NM used, various phenomena are responsible for altering the cementitious composites' properties. NMs can act as the nucleation seeds for the hydration reaction of the cement which results in earlier formation of the $\mathrm{C}-\mathrm{S}-\mathrm{H}$ phase and, in turn, substantial effect on the thixotropic properties and strength evolution of composites (Land and Stephan 2012; Sikora et al. $2020 b$ ). Through the pozzolanic reaction of nanomaterials (i.e. silica nanoparticles) with calcium hydroxide $(\mathrm{CH})$, the amount of calcium silicate hydrate $(\mathrm{C}-\mathrm{S}-\mathrm{H})$ gel increases, which in turn affects the strength and durability of composite (Skoczylas and Rucińska 2018). Moreover, nanosized particles fill the voids in the cement matrix, decreasing paste porosity and refining the pore structure

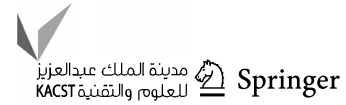


Table 1 Nanoclay, graphene-based materials and nanosilica additions in printable mixtures

\begin{tabular}{|c|c|c|c|c|c|}
\hline Type of NM & Specification & Quantities & Optimum & Effect & References \\
\hline \multirow[t]{4}{*}{ Nanoclay } & $\begin{array}{l}\text { Highly purified attapulg- } \\
\text { ite nanoclay }\end{array}$ & $\begin{array}{l}0-0.1-0.3-0.5 \% \text { by mass } \\
\text { of binder }\end{array}$ & $0.5 \%$ by mass of binder & $\begin{array}{l}\text { Increment in cohe- } \\
\text { sion and static yield } \\
\text { strength }\end{array}$ & Qian et al. (2019) \\
\hline & $\begin{array}{l}\text { Highly purified magne- } \\
\text { sium alumino silicate } \\
\text { clay }\end{array}$ & $0-3 \%$ by mass of cement & $\begin{array}{l}0.5-1 \% \text { by mass of } \\
\text { cement }\end{array}$ & $\begin{array}{l}\text { Facilitates re-floccu- } \\
\text { lation and improves } \\
\text { the thixotropy of the } \\
\text { mixture }\end{array}$ & Quanji et al. (2014) \\
\hline & Nano-attapulgite clay & $\begin{array}{l}0.1-0.5 \% \text { by mass of } \\
\text { binder }\end{array}$ & $0.5 \%$ by mass of binder & $\begin{array}{l}\text { Increment of the static } \\
\text { yield stress without } \\
\text { significantly affecting } \\
\text { the apparent viscosity }\end{array}$ & Panda et al. (2019c) \\
\hline & $\begin{array}{l}\text { Hydrophilic bentonite } \\
\text { nanoclay }\end{array}$ & $\begin{array}{l}0.5-1 \% \text { by mass of } \\
\text { solids }\end{array}$ & - & $\begin{array}{l}\text { Thickening effect, incre- } \\
\text { ment in the static yield } \\
\text { strength }\end{array}$ & $\begin{array}{l}\text { Mendoza Reales et al. } \\
\text { (2019) }\end{array}$ \\
\hline \multirow[t]{3}{*}{ Nanosilica } & - & $\begin{array}{l}0.5-1 \% \text { by mass of } \\
\text { solids }\end{array}$ & - & $\begin{array}{l}\text { Increment in the veloc- } \\
\text { ity of the structural } \\
\text { build-up of the paste }\end{array}$ & $\begin{array}{l}\text { Mendoza Reales et al. } \\
\text { (2019) }\end{array}$ \\
\hline & - & $\begin{array}{l}0.5-2-3.5 \% \text { by mass of } \\
\text { cement }\end{array}$ & $3.5 \%$ by mass of cement & $\begin{array}{l}\text { Reduction of plastic } \\
\text { shrinkage }\end{array}$ & Sonebi et al. (2015) \\
\hline & - & $\begin{array}{l}1,2,3 \% \text { by mass of } \\
\text { cement }\end{array}$ & $1 \%$ by mass of cement & $\begin{array}{l}\text { Increment in the re- } \\
\text { flocculation rate }\end{array}$ & Kruger et al. (2019b) \\
\hline $\begin{array}{l}\text { Graphene- } \\
\text { based } \\
\text { materials }\end{array}$ & $\begin{array}{l}\text { Nano graphite platelets } \\
\text { (NGPs) }\end{array}$ & $\begin{array}{l}0.1-1.0 \% \text { by mass of } \\
\text { binder }\end{array}$ & $1.0 \%$ by mass of binder & $\begin{array}{l}\text { Efficient rheology } \\
\text { modification agent and } \\
\text { improves the mechani- } \\
\text { cal performance }\end{array}$ & Chougan et al. (2020a) \\
\hline
\end{tabular}

(Sikora et al. 2020a) and lead to the bridging and blocking effect which improve the toughness of the composites (Chougan et al. 2020b).

Table 1 presents the summary of recent studies related to the incorporation of NMs to 3D printable composites.

\section{Effects of nano- and micro-sized particles}

\section{Silicon-based, graphene-based, and clay nanoparticles: fresh properties}

Cementitious mixtures being implemented in 3D printing processes should be flowable enough to be pumped and extruded through a hose/nozzle, as well as gain sufficient strength and stiffness to retain its shape after layer-by-layer deposition of printed material (Tay et al. 2019; Albar et al. 2020). Therefore, the impact on rheology and the workability of cementitious materials in a fresh state is a crucial factor that should be considered when choosing additives.

Silica nanoparticles $\left(\mathrm{SiO}_{2}\right)$, or nanosilica (NS), are one of the most popular admixtures used in the modification of conventional concretes. This effect is attributed to their significant chemical and physical interactions occurring during cement hydration process such as: pozzolanic activity, nucleating and nano-filling effect resulting in earlier formation of
C-S-H phase and, in turn, a substantial effect on the thixotropic properties and early strength development of pastes. The quantity of NS used in studies varies from 0.5 to $3 \%$ by mass of cement (Sonebi et al. 2015; Kruger et al. 2019b; Mendoza Reales et al. 2019). The addition of NS increases the flocculation rate and improves the material's buildability (Kruger et al. 2019b) when increasing the structural buildup of the material, due to its nanometric scale and chemical nature (Mendoza Reales et al. 2019). Thus, NS was found to have a significant effect to be used as a thickening agent. Study conducted by Mendoza Reales et al. (2019) showed that NS is extremely effective in increasing the static yield stress as well as the rate of thixotropic build-up in the $3 \mathrm{D}$ printable Portland cement pastes (Fig. 4c).

In the study of Kruger et al. (2019b), the effects of 1, 2, 3 wt $\%$ of NS was evaluated on the rheological properties of 3D printable concretes. Study confirmed that NS increases the reflocculation rate. The highest rate of $8 \mathrm{~Pa} / \mathrm{s}$ was achieved with addition of $1 \mathrm{wt} \%$ of NS. In contrast, higher dosages of NS were found to significantly lower re-flocculation rates, thus resulting in negative influence on thixotropic behaviour. In addition, the extensive dosage of NS resulted in significant increment in the long term dynamic shear stress, thus mixture with $3 \mathrm{wt} \%$ of NS was suitable for 3D printing at the 40-min time interval (Fig. 5). In the work of Cho et al. (2020), positive effect of $2 \mathrm{wt} \%$ of NS was observed 

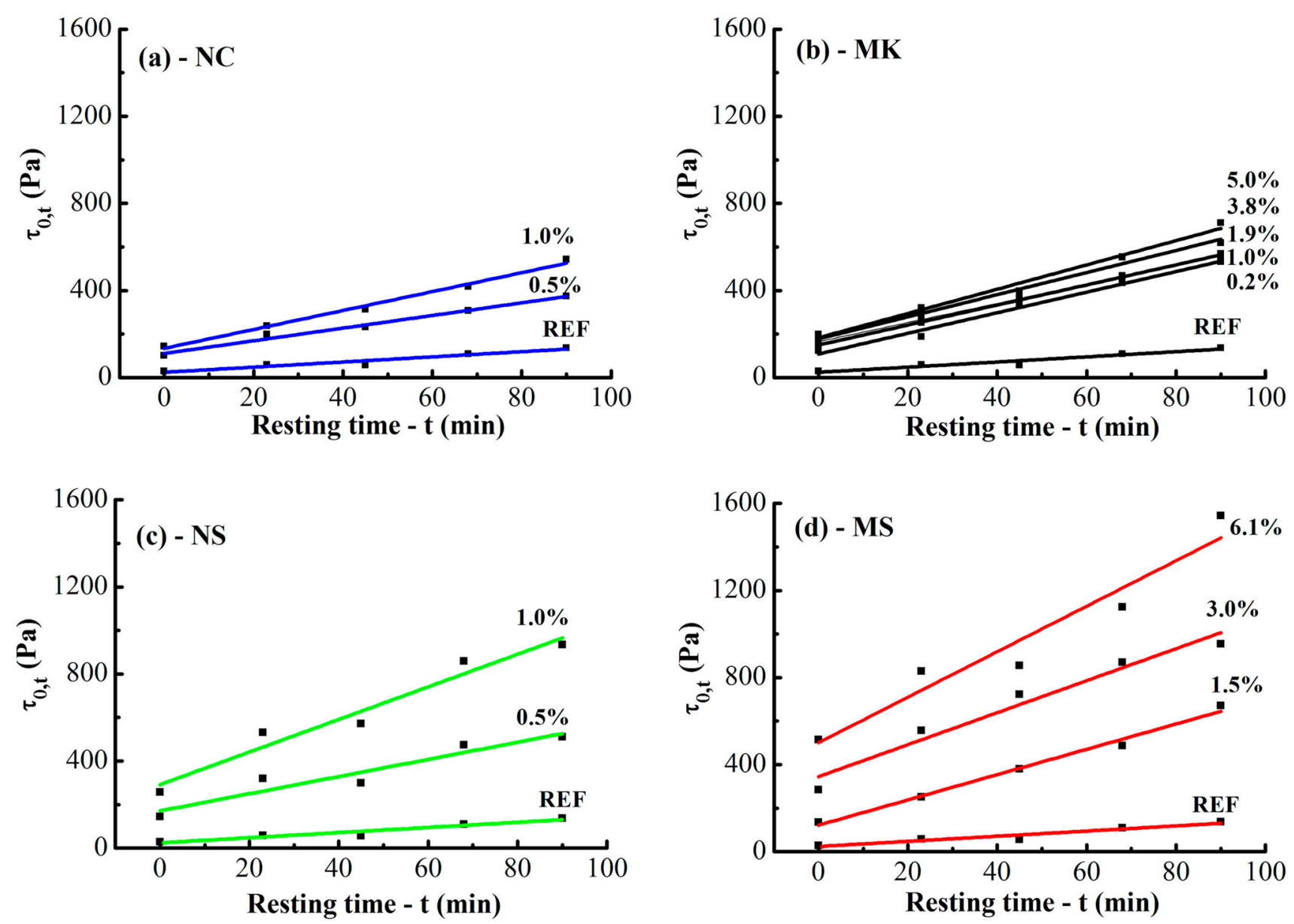

Fig. 4 Static yield stress versus different resting time and linear fits for pastes containing a nanoclay, $\mathbf{b}$ metakaolin, $\mathbf{c}$ nanosilica and $\mathbf{d}$ silica fume used as a cement replacements of 3D printable cement

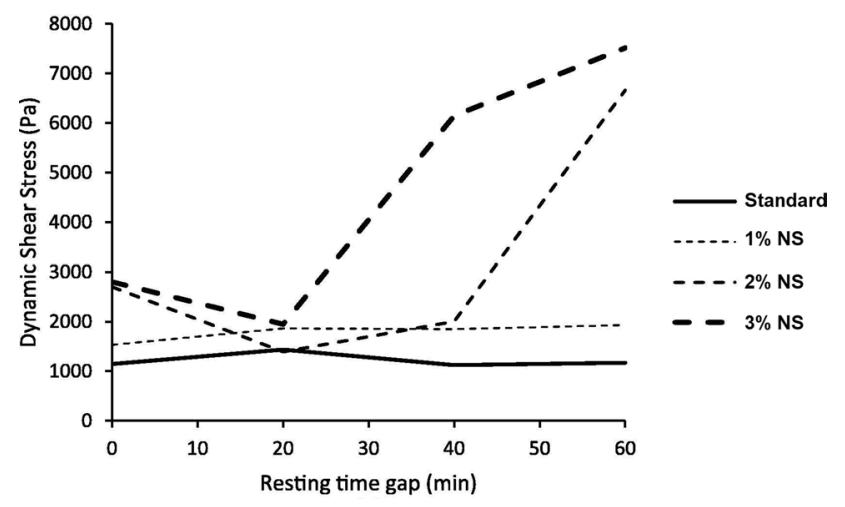

pastes. Reprinted from Mendoza Reales et al. (2019) with permission from Elsevier, 2019

Another group of materials, are clay nanoparticles which have shown great potentials for 3D printing mix modifications. Similar to NS, clay nanoparticles are known to work effectively as a thickening agent that can be attributed to flocculation of the clay particles, their high water adsorption, or a possible interaction between the clays and ettringite (Mendoza Reales et al. 2019). In 3DPC, clay is frequently used in the form of micro-particles and nanoclay to alter the rheological behaviour and structural build-up. Various types of clay are used, which have diverse impacts on the properties, such as purified magnesium aluminosilicate, metakaolin, kaolinite, illite, among others. (Voigt et al. 2010; Gao et al. 2012). The quantity of micro-particles of clay used

Fig. 5 Dynamic shear stress versus resting time gap depending on nanosilica (NS) content. Reproduced from Kruger et al. (2019b) with permission from Elsevier, 2019

for optimizing the rheological and structural properties of a printable mixture. Thus, the buildability of lightweight foamed printable concrete was improved. in studies varies up to $0.24 \%$ by mass of binder (Gao et al. 2012; Chen et al. 2020b) and nanoclay percentages varies between 0.3 to $4.5 \%$ by mass of binder (Quanji et al. 2014; Marchon et al. 2018; Qian et al. 2019; Panda et al. 2019b, 2020).

The addition of nanoclay, in general, increases the thixotropic behaviour (Quanji et al. 2014) due to the flocculation 
effect (Marchon et al. 2018; Panda et al. 2019b, 2020). Several researchers have reported optimum quantities of nanoclay that improve thixotropy, such as $0.5-1 \%$ (Quanji et al. 2014) and $0.5 \%$ of the mass of cement (Qian et al. 2019). However, the incorporation of a quantity higher than $1.3 \%$ of the mass of cement decreases the rate of thixotropy (Quanji et al. 2014). Nanoclay improves fresh stage stiffening, due to its effect in the acceleration of the building kinetics and the increase of the static yield stress (Marchon et al. 2018; Mendoza Reales et al. 2019) (Fig. 4a). According to Qian et al. (2019), cohesion and static yield stress increases with increasing nanoclay addition to the mixture. Among some possible mechanisms, nanoclay strengthens the fresh microstructure by a filling effect and interparticle linkage. In the work of Zhu et al. (2019), $0.5 \mathrm{wt} \%$ attapulgite nanoclay (ANC) was used as a thixotropy improving admixture in ultra-high tensile ductile engineered cementitious composites. The study confirmed its beneficial effect on the printability. Similarly in Rubio et al. (2017) study, it was confirmed that even low dosage of nanoclay $(0.1 \mathrm{wt} \%)$ has beneficial effect on increasing the suspension viscosity and flocculation, thus improving structural stability, facilitating better extrusion and a longer open time. Panda et al. (2019c) also evaluated the effects of low dosage of ANC $(0.1-0.5 \mathrm{wt} \%)$ on the properties of high volume fly ash printable mixtures. Study showed that nanoclay increased the static yield stress of printable mortars without significantly affecting the apparent viscosity, due to particle re-flocculation and enhanced thixotropy. Incorporation of $0.5 \mathrm{wt} \%$ of nanoclay increased viscosity recovery as well as improving the structural build-up at different resting times and shear rates. High-yield stress led to improving the buildability and decreasing the deformation of the mortar during the printing process (see Fig. 6).

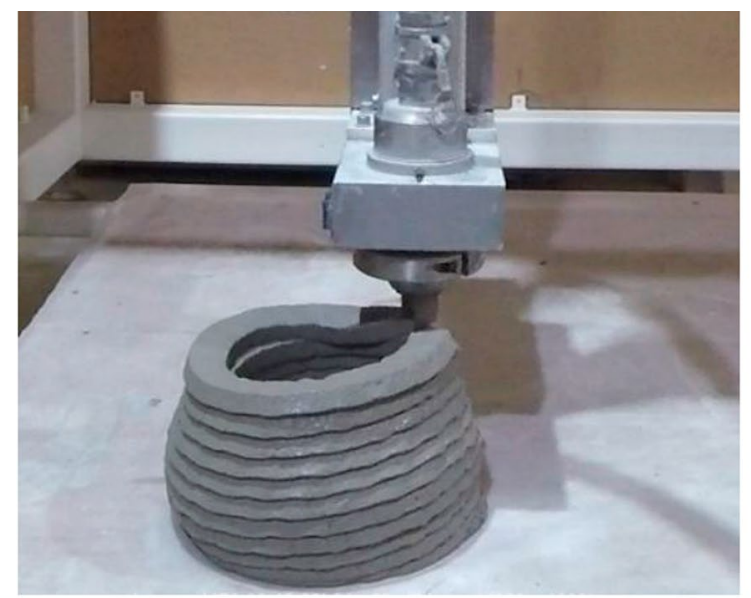

Silicon carbide ( $\mathrm{SiC}$ ) nanoparticles were also proposed as a potential thixotropy improving agents in the 3D printable concretes. Kruger et al. (2019a) performed the comparative study between the effects of 1, 2 and $3 \mathrm{wt} \%$ of silica and $\mathrm{SiC}$ nanoparticles on the fresh properties of 3D-printed concretes. Study showed distinct differences between the performance of $\mathrm{SiC}$ and nanosilica. Due to significant discrepancy between surface area ratios of nanosilica and $\mathrm{SiC}$ (i.e. 16:1), clear differences in rheological effects were observed. SiC nanoparticles had significant effect on improving thixotropic behaviour of concrete, while, nanosilica noticeably affected the static yield shear stress. In addition, higher dosages of nanosilica ( 2 and $3 \mathrm{wt} \%$ ) led to an extremely stiff mix, that is not suitable for printing.

Several types of graphene derivatives including, graphene nanoplatelets (GNPs), nano-graphite platelets (NGPs), graphene oxide (GO), reduced graphene oxide (rGO), as well as carbon nanotubes (CNTs) are introduced as relatively novel and advanced inclusions in cementitious composites. Graphene-based materials (GBMs) are characterized by their high tensile strength $(\sim 130 \mathrm{GPa})$ and elastic modulus $(\sim 1$ $\mathrm{TPa}$ ), as well as their rheology modification nature (thixotropy), which makes them a suitable candidate for incorporation in cementitious composites (Soldano et al. 2010; Alkhateb et al. 2013). Graphene-reinforced cementitious composites are made by adding and mixing discontinuous randomly distributed graphene particles within a cementitious composite mixture. It has been established that the use of GBMs within cementitious composites has many benefits, including improved fresh and mechanical properties (Shang et al. 2015). Due to the newly emerging nature of AM, limited amounts of studies have been conducted on the utilization of GBMs reinforcement in 3D printable mixtures. Therefore, this section will explore the relevant available literature surrounding GBMs-reinforced cementitious

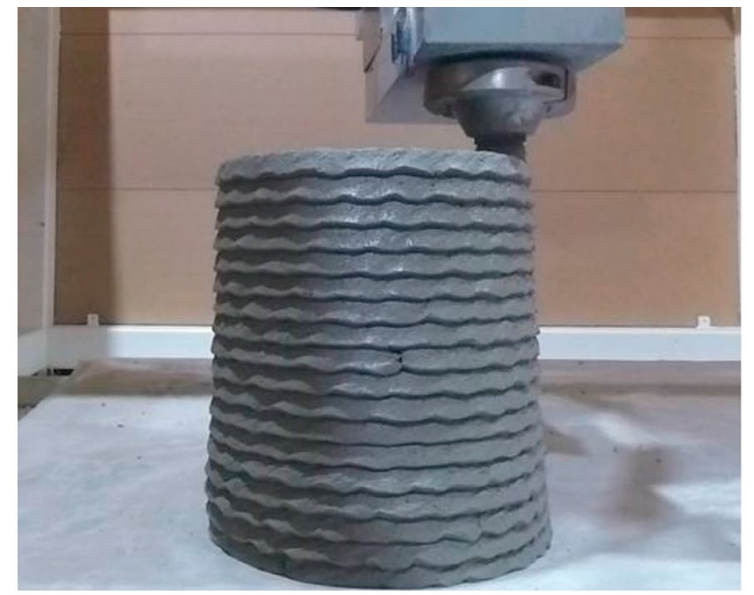

Fig. 6 Buildability of the control (left) and $0.5 \mathrm{wt} \%$ nanoclay incorporated (right) printable mortars. Reproduced from Panda et al. (2019c) with permission of Elsevier, 2019 
composites, both traditionally casted and printed, to gauge the potential benefits these reinforcement materials can have on the fresh properties of a cementitious mixture. It is well accepted that the fresh properties of GBM-modified cementitious composites are highly dependent on the dosage, the number of wrinkles on the particle's surface, oxygen content and the dimension of GBMs (Chougan et al. 2019). The presence of GBM particles within the cementitious composites in one hand can induce the lubrication effect in specific dosages, which decreases the rheology values (Zhu et al. 2012). However, on the other hand, the super water sorbent nature of these particles consume the mixes' moisture, leading to the increased rheology values such as yield shear stress, plastic viscosity and apparent viscosity (Pan et al. 2015; Jing et al. 2017). Chougan et al. (2019) confirmed that in the case of sample modified with the large-sized GNPs (i.e. average lateral size: $30 \mu \mathrm{m}$ ) in special dosages, the lubrication effect dominated over the thickening effect, resulting in the decreased rheology values.

During the 3D printing process, it is desirable to have a cohesive mixture that demonstrates sufficient rheology values to obtain a stable structure with minimum deformation while maintaining its extrusion performance. Chougan et al. (2020a) investigated the effects of different volume fractions of nano-graphite particles (i.e. $0.1-1.0 \%$ by the weight of binder) on the multi-binder [i.e. fly ash (FA), ground granulated blast furnace slag (GGBS), and silica fume (SF)] printable geopolymer properties. The results of this study indicate that the inclusion of nano-graphite particles improved the geopolymers fresh properties by inducing shear-thickening effect in specific dosages (i.e. $0.3 \mathrm{wt} \%$ and $1.0 \mathrm{wt} \%$ ) compared to the control mix. The most remarkable improvements on rheology parameters including, yield shear stress (i.e. 96\%) and plastic viscosity (i.e. 56\%), were exhibited for those composites loaded with $1.0 \%$ nano-graphite
(Chougan et al. 2020a). Aligned with the findings above, Zhong et al. (2017) also reported that shear-thickening behaviour is needed to print geopolymer inks. The results indicated that the incorporation of GO particles improves the geopolymer's rheology performance, which enables the geopolymer mixture to be extruded smoothly while retaining its shape after printing. For instance, as highlighted in Fig. 7, at the constant stress of $50 \mathrm{~Pa}$, which is generally experienced during the actual 3D printing process, the addition of $4.59 \mathrm{vol} \%$ of GO increases the loss and storage modulus to $1.5 \times 10^{4} \mathrm{~Pa}$ and $1.0 \times 10^{5} \mathrm{~Pa}$, respectively, which are considerably higher (by 100-200\%) than those values registered for the control sample. However, due to the lubrication behavior, the inclusion of higher dosages of GO particles (i.e. 5.66 vol\%) decreased the corresponded rheology parameters (Zhu et al. 2012; Zhong et al. 2017). In another study, Zhou et al. (2020) investigated the effects of GO lateral size on the fresh property performance of 3D-printed geopolymer inks. The outcomes of this study (see Fig. 7) showed that the rheology of the cementitious composites is drastically related to the GO particle's dimension in which the addition of large-size GO particles increased the storage and loss modulus compared to that of small-size GO particles and neat geopolymer (Zhou et al. 2020).

\section{Silicon-based, graphene-based, and clay nanoparticles: hardened properties}

Despite relatively well-recognized effects of nanosized admixtures on the fresh properties of 3D-printed cementitious composites the data related to the hardened properties is relatively limited. Since nanomaterials have significant effects on acceleration of the hydration process and faster formation of the "strength-giving" phases, incorporation of nanomaterials seems to be an attractive solution toward
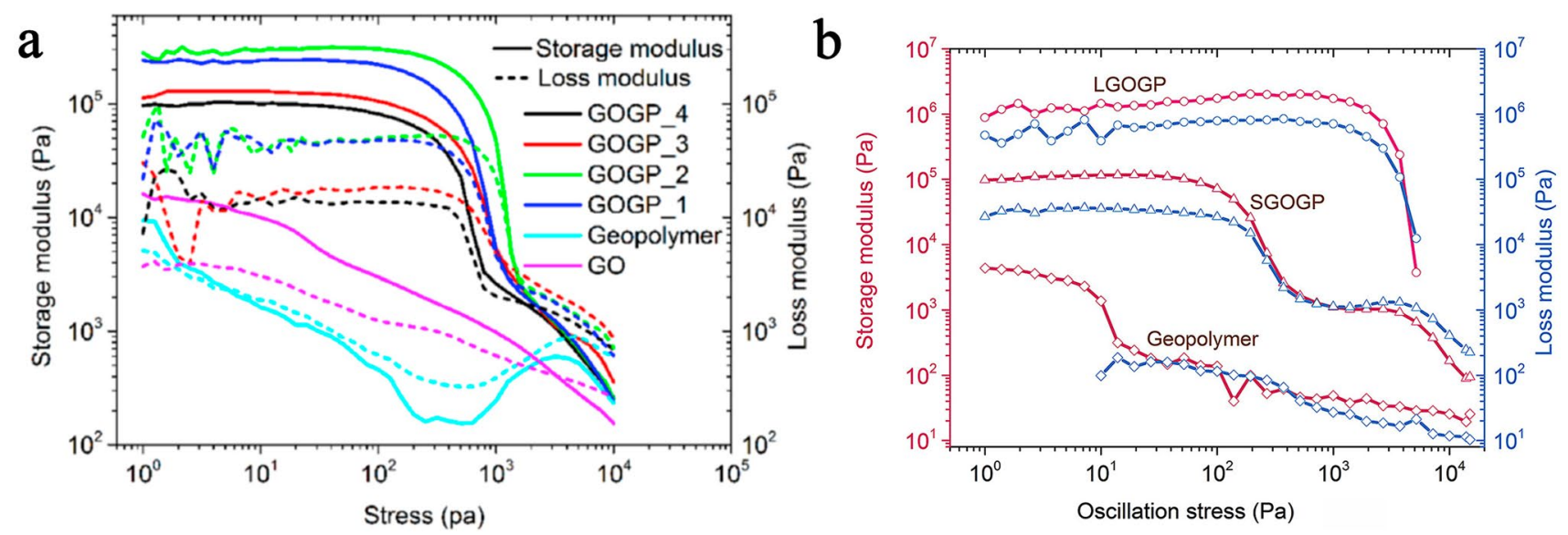

Fig. 7 Rheology properties, i.e. shear modulus vs. shear stress. of the GO/geopolymer ink, a Zhong et al. (2017), b Zhou et al. (2020). Reproduced with permission from Elsevier 

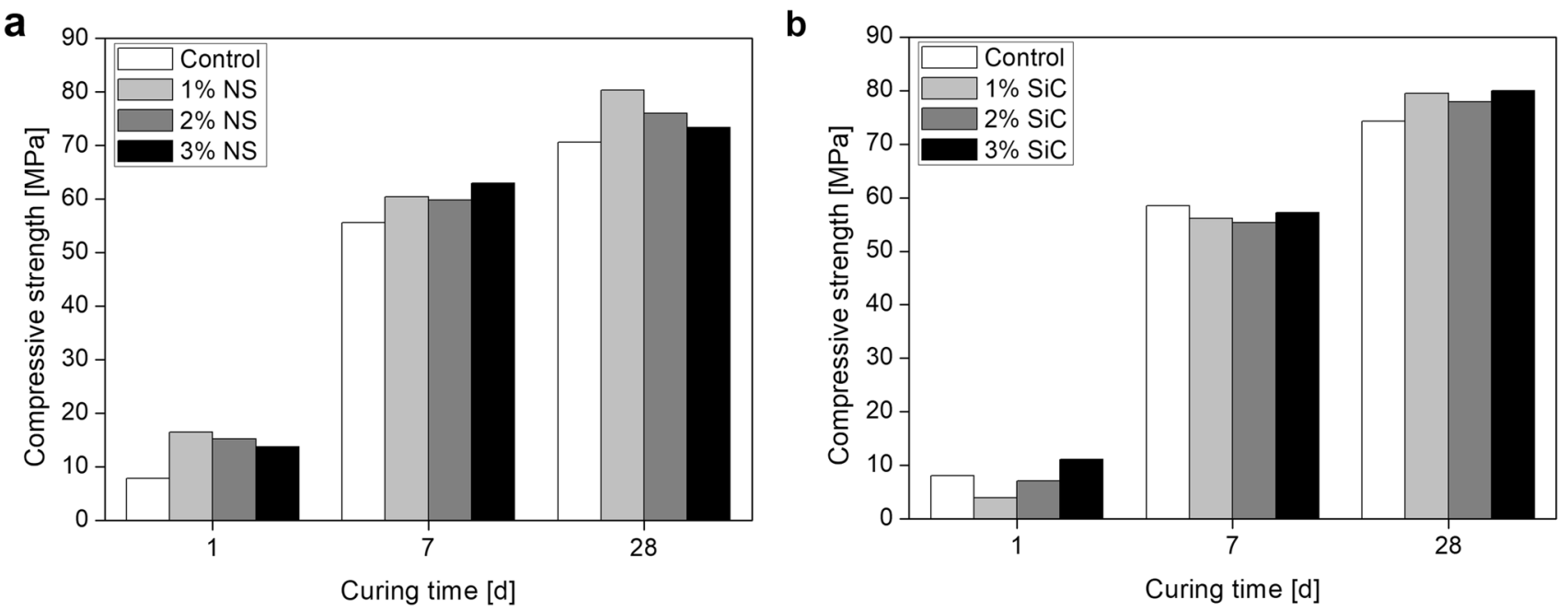

Fig. 8 Compressive strength development of 3D-printed concretes containing 1, 2, 3 wt\% admixture of NC (left) and SiC nanoparticles (right). Data taken from Kruger et al (2019a)
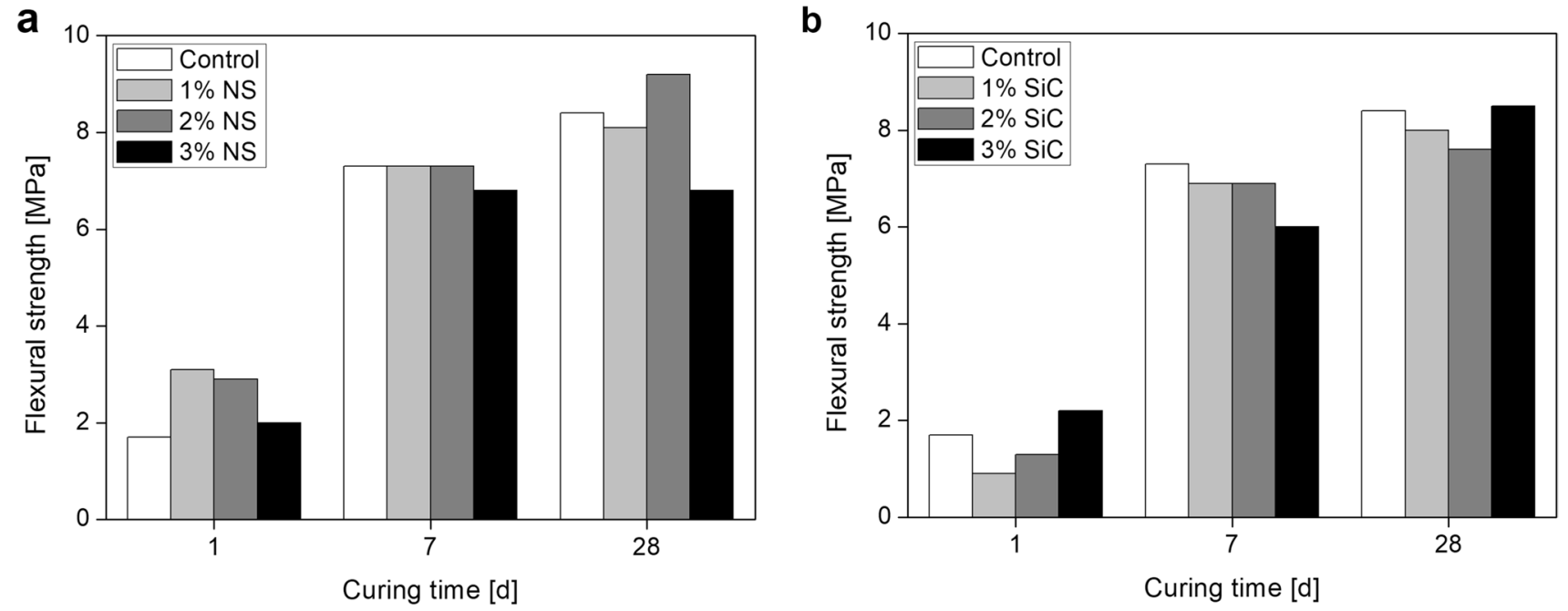

Fig. 9 Flexural strength development of 3D-printed concretes containing 1, 2, 3 wt\% admixture of NC (left) and SiC nanoparticles (right). Data taken from Kruger et al. (2019a)

improving the early strength development of printable composites. In the work Kruger et al. (2019a) the effects of 1, 2 and $3 \mathrm{wt} \%$ of $\mathrm{NC}$ and $\mathrm{SiC}$ nanoparticles on the mechanical properties of 3D-printed concrete were evaluated. Significant improvement of the early compressive (Fig. 8) and flexural (Fig. 9) strengths were reported in concrete containing nanosilica, while in case of SiC-incorporated specimens, early strength development remained slightly hindered. Incorporation of $1 \mathrm{wt} \%$ of nanosilica resulted in improvement of compressive and flexural strength by $88 \%$ and $82 \%$ (respectively), when compared to control specimen. Moreover, addition of both nanomaterials resulted in improvement of interlayer bond strength (IBS). Similarly Cho et al. (2020) reported that $2 \mathrm{wt} \%$ of NC had significant effects on increasing flexural strength, compressive strength and E-modulus in the lightweight printable foamed concretes.

Study on the compressive strength of the high-volume fly ash printable mortars modified with $0.5 \mathrm{wt} \%$ nano attapulgite clay confirms noticeable effect on the 28 days compressive strength (Panda et al. 2019c). In contrary, decrease on the tensile bond strength, especially with increasing the gap time during printing, was reported (Fig. 10).

The underpinning reason for the reduction of tensile bond strength is associated with the thixotropic property of the 


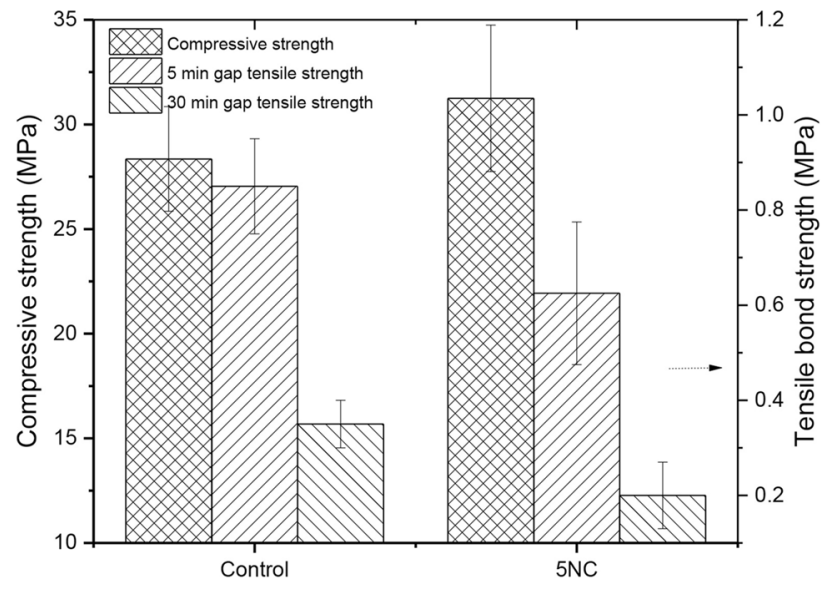

Fig. 10. 28 days compressive and tensile bond strengths of control mortar and mortar containing $0.5 \mathrm{wt} \%$ of nano attapulgite clay (5NC). Reprinted from Panda et al. (2019c) with permission of Elsevier, 2019

NC-incorporated mortar, which results in built up of the yield stress at the bottom layer, before placing subsequent layers. This subsequently leads to weak interface between layers. Similar observation was found in study from Panda et al. (2019a), where NC-incorporated 3D-printed concrete had higher quantities of macropores in the interface, as compared to control concrete, as a result of their increased thixotropy (Fig. 11).

Many studies have indicated the potential of GBMs to increase the mechanical properties of cementitious composites such as its compressive, tensile, and flexural strength (Singh et al., 2011; Sharma and Kothiyal 2015; Rhee et al. 2016). Lv et al. (2013) reported that the inclusion of 0.02 wt\% (by the weight of cement) GO particles increased the tensile, compressive and flexural strength of final products by $197 \%, 160 \%$ and $184 \%$, respectively. The findings of Lv et al. (2013) are also supported by that of Chougan et al. (2020b), who also found that an increase in the nanographite particle content from 0.01 to $0.2 \mathrm{wt} \%$ leads to a proportional increase in compressive and flexural strength of the cementitious specimens. Another study by Ranjbar et al. (2015) explored the impact GNPs inclusion with the dosages of $0.1 \%, 0.5 \%$ and $1 \%$ on mechanical properties of geopolymer composites containing fly ash. Their results displayed remarkable improvements of $216 \%$ and $144 \%$ for flexural and compressive strength, respectively. In contrast to the findings of the aforementioned studies showing the positive impact of GNPs incorporation on the mechanical property efficiency of the cementitious composites, Hou et al. (2017) highlighted that addition of $0.16 \mathrm{wt} \%$ graphene particles (GNPs) has a negative impact on compressive and flexural strength of the samples and reduced them by $3.36 \%$ and $10.5 \%$, respectively. Past studies have been reviewed to assess the compatibility of GBMs within cementitious composites. However, the changes in mechanical performance are evaluated when the composite is traditionally casted. Only a few studies investigated the role of GBMs inclusion in the 3D-printed cementitious composites. Further to fresh properties, Chougan et al. (2020a) also explored the impact of nano-graphite incorporation with the dosages of $0.1 \%, 0.3 \%, 0.5 \%$, and $1 \%$ on the mechanical performance of 3D-printed geopolymer composites and compared to the corresponding traditionally casted samples (Fig. 12). The results showed that the inclusion of nano-graphite particles has a positive impact on the samples' mechanical properties after 7 days of curing. The flexural strength of printed objects was shown to continuously increase with nanographite particle content, with the maximum strength value of $15.3 \mathrm{MPa}$ being achieved with a particle dosage of $1 \%$. This is an increase of $46 \%$ compared to the control sample. Moreover, the compressive strength of the 3D-printed samples loaded with $1 \%$ NGPs were increased by $14 \%$ compared to the control sample. This is due to the fact that a denser multi-binder geopolymer material will have a more compact
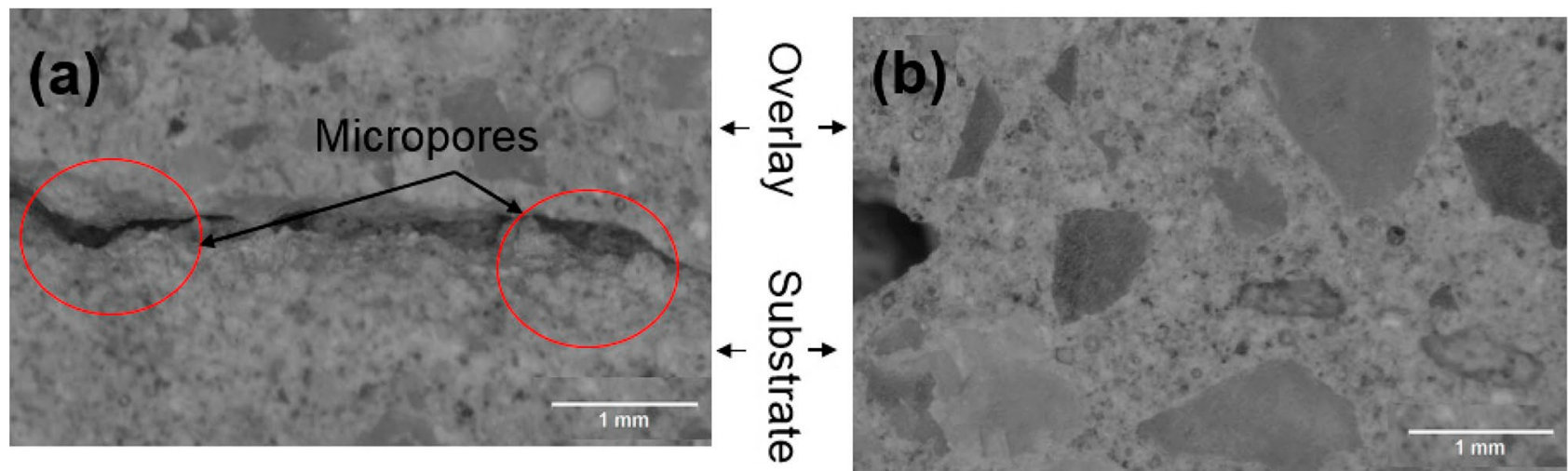

Fig. 11 Scanning electron microscopy of specimens containing $0.5 \mathrm{wt} \%$ nanoclay (a) and control specimen (b). Reproduced from Panda et al. (2019a) 

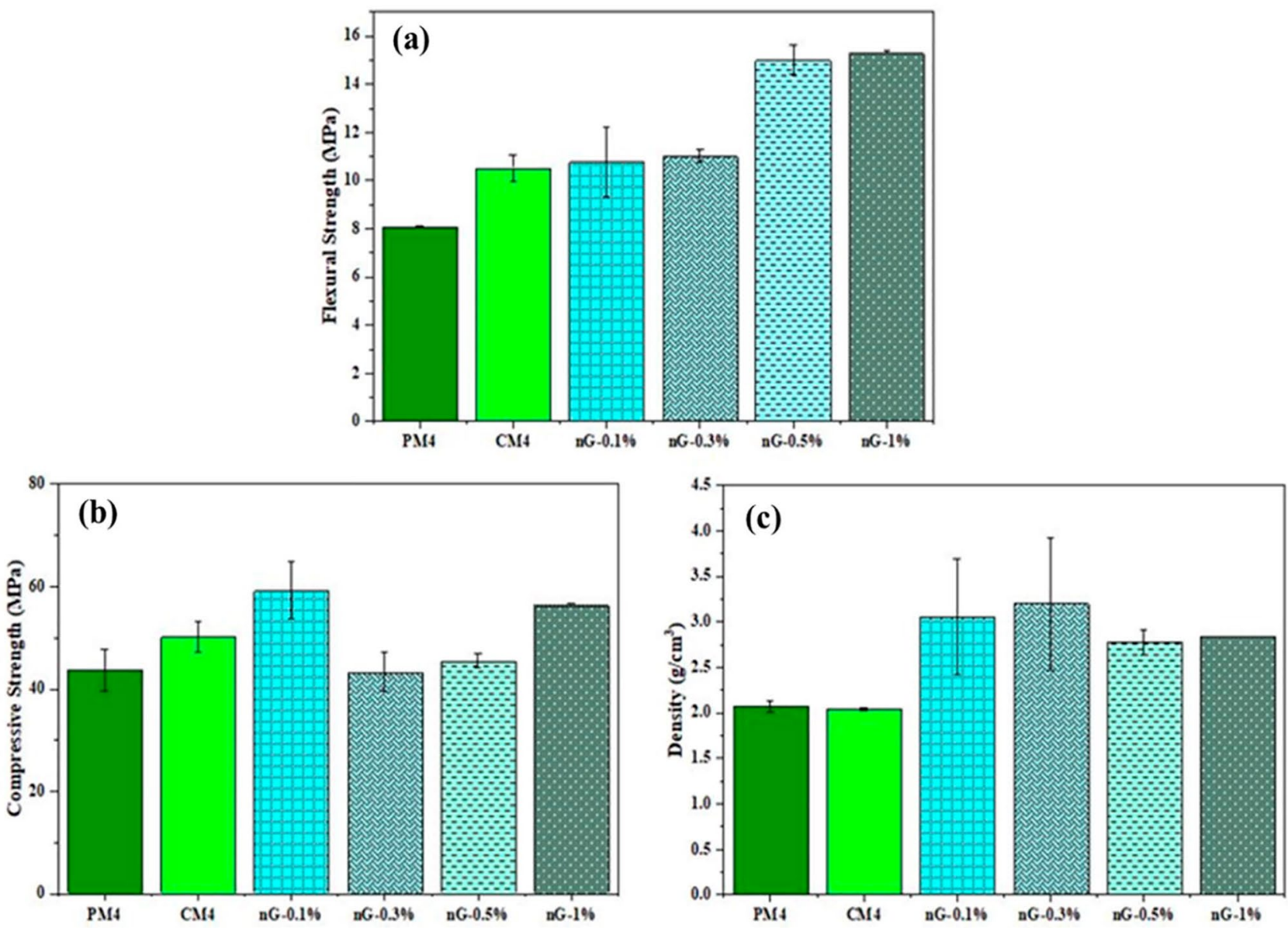

Fig. 12 Printed (PM) and casted (CM) geopolymer mixes modified with different NGP dosages a flexural strength, b compressive strength and $\mathbf{c}$ densities. Reprinted from Chougan et al. (2020a)

matrices with fewer air voids and lower porosity. The void volume reduction results in limited crack propagation and therefore improves the external loading resistance capacity of composites.

Zhong et al. (2017) also employed graphene oxide (GO) particles in geopolymers for 3D printing. They investigated the effect of GO loading dosage on the mechanical property and electrical conductivity of printed samples. Their results revealed that increasing the GO dosage form 4 to $10 \mathrm{wt} \%$ (by the weight of aluminosilicate particles) induced improvements in compressive strength and elastic modulus of the printed nanocomposites. However, due to the nanoparticle agglomeration phenomena, the incorporation of excessive GO particles (i.e. $20 \mathrm{wt} \%$ ) diminishes both elastic modulus and compressive strength of the printed samples (Zhong et al. 2017). Zhou et al. (2020) reported the impact of GO lateral size on the geopolymer nanocomposites. The results revealed that GO particles' inclusion could modify the rheology of geopolymers and make the composite suitable for 3D printing. Moreover, they reported that the addition of small size particles in geopolymer is more promising in terms of compressive strength, elastic modulus, tensile strength and fracture strain comparing to the utilization of large-size particles (Zhou et al. 2020).

\section{Comparison of the effects of ultra and nanosized admixtures}

Comparative study evaluating the effects of two groups of micro- and nanosized admixtures was conducted (Mendoza Reales et al. 2019), where silica fume versus nanosilica and nanoclay versus metakaolin led to several interesting conclusions. It was found that nanosized admixtures were more effective in increasing the static yield stress as well as the rate of thixotropic build-up (Fig. 4). For instance, with the use of nanosilica particles, only $1 / 3$ of the amount was required to achieve comparable properties 
Table 2 Efficiency of the different micro- and nanosized admixtures on the rheological parameters of the printable cement paste, normalized by solid substitution. Data reproduced from Mendoza Reales et al. (2019)

\begin{tabular}{lllll}
\hline Particle & $\begin{array}{l}A_{\text {thix }} / \text { solid substitution } \\
(\mathrm{Pa} / \min \%)\end{array}$ & $\begin{array}{l}\tau_{0 \text {,fit }} / \text { solid substitu- } \\
\text { tion }(\mathrm{Pa} / \%)\end{array}$ & $\begin{array}{l}h_{\text {max }} / \text { solid substitu- } \\
\text { tion }(\mathrm{cm} / \%)\end{array}$ & $\begin{array}{l}h_{\text {printable }} / \text { solid } \\
\text { substitution } \\
(\mathrm{cm} / \%)\end{array}$ \\
\hline Nanosilica & 7.5 & 291 & 2.7 & 0.15 \\
Microsilica & 1.7 & 82 & 0.8 & 0.03 \\
Nanoclay & 4.4 & 134 & 1.3 & 0.13 \\
Metakaolin & 1.1 & 37 & 0.3 & 0.03 \\
\hline
\end{tabular}

$A_{\text {thix }}$ rate of thixotropic build-up, $\tau_{0, f i}$ static yield stress, $h_{\max }$ maximum layer height, $h_{\text {printable }}$ critical layer height as in the case of microsilica. Based on the chemical composition, silica nanoparticles were more efficient than clay nanoparticles in modifying rheological properties normalized per solid substitution (Table 2). Thus, NS when compared to $\mathrm{NC}$ is much more effective in improving the fresh properties of cementitious composites. Zhang et al. (2018) conducted a comparative study on the effects of NC and silica fume (SF) admixtures on 3D printing mixtures. Cement was replaced with $2 \mathrm{wt} \%$ of admixture. In addition, samples containing both admixtures in total amount of $4 \mathrm{wt} \%$ were produced. It was shown that both admixtures can enhance the thixotropy and buildability of 3D-printed concrete, with a higher rate of increase corresponding to the use of nanoclay (compared to silica fume). Ad-hoc buildability test confirmed that control mix was able to build $72 \mathrm{~mm}$ heights while mixtures containing SF and NC reached 163 and $180 \mathrm{~mm}$, respectively. Incorporation of both admixtures simultaneously to the mixture enabled the buildability of $260 \mathrm{~mm}$ height object. Incorporation of SF and NC resulted in a reduction of flow by $7 \%$ and $9 \%$, while combination of admixtures resulted in a reduction of $10 \%$.

To the best of authors' knowledge, there is no literature that compares the effectiveness of GBMs with other types of additives. However, as previously mentioned, interlayer bonding, flexural strength and ductility are key attributes that 3D-printed cementitious composites are known to be weak in. GBMs reinforcement can improve these properties through three important events:

1. Bridging and blocking effect that enables for efficient load transfer across cracks, increasing the amount of energy that can be absorbed in the tension zone of the cementitious composites as well as preventing sudden failure (Ranjbar et al. 2014). Crack-bridging particles not only improve post-cracking behaviour but also contribute to keeping micro-cracks from spreading by sewing them together (Ranjbar et al. 2015).

2. Pore refinement process promoted by the presence of the GBMs. Being a pozzolanic material at a nanoscale size enables the GBMs to improve the bonding between hydration products of binders and GBMs particles [i.e. 13.5 GPa for GO, and 1.2 GPa for GNPs (Alkhateb et al. 2013)] as well as refine the pore structure by reducing the porosity of the composite matrices (Horszczaruk et al. 2015; Sharma and Kothiyal et al. 2015).

3. Acceleration in the binder's hydration kinetics acts as a catalyst and heterogeneous nucleation site (Chougan et al. 2019).

\section{Polymeric admixtures in 3D printable cementitious matrices}

Despite the fact that polymeric admixtures can influence the rheological behaviour of cementitious matrices significantly and may tailor their hydration kinetics over a wide range (Jolicoeur and Simard 1998; Cheung et al. 2011; Liu et al. 2019), research on the application of such additives with regards to $3 \mathrm{D}$ printing is mainly governed by empirical approaches for applicable mix designs. To reduce water drainage (Perrot et al. 2018) most widely used polymeric admixtures for tailoring 3D printable cementitious materials are the family of viscosity modifying agents (VMA). Polysaccharidic macromolecules, in particular welan and diutan gum may result in a very prominent thixotropic behaviour (Reiter et al. 2018). According to (Marchon et al. 2018), polyacrylamide is the most suitable VMA for printable concrete, since it limits the deformation behaviour of deposited material clearly. Moeini et al. (2020) used VMA 1 $\mathrm{wt} \%$ modified starch in combination with a polycarboxylate ether (PCE)-based as high-range water-reducer and reported a considerable increase in early age strength. An hybridized additive system based on $1 \mathrm{wt} \%$ nanoclay and $1 \mathrm{wt} \%$ low molecular weight cellulose ether was found by Douba et al. (2020) to tailor yield stress and plastic viscosity of cement paste to meet the demand for a good buildability of complex geometries.

Frequently, also hydroxypropyl methylcellulose (HPMC) is used as VMA, which is reported to influence the hydration process and microstructure of cementitious matrices, seen in an increase of portlandite and void formation (Chaves

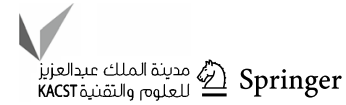


Figueiredo et al. 2019a). For limestone calcined clay cement $\left(\mathrm{LC}^{3}\right)$-based matrices $0.24 \mathrm{wt} \%$ HPMC and $2 \mathrm{wt} \%$ superplasticizer were found for achieving good shape stability, buildability, and green strength by relatively small extrusion pressures (Chen et al. 2019, 2020b). Those ratios were also used for assessing different grade levels of calcined clays (Chen et al. 2020d) as well as printing parameters (Chen et al. 2020c).

A parameter study on printable strain-hardening cementitious composites with varied, undescribed VMA and PCE contents showed that after the liquid/solid ratio, the use of VMA is a key factors to control the mixture stability and fibre dispersion, whereby the amount of superplasticizer is of less importance (Chaves Figueiredo et al. 2019b).

To achieve a desired setting on demand (Reiter et al. 2020), VMA modified matrices were also combined with retarders or accelerator to enhance processing and setting time, respectively. $\mathrm{CaCl}_{2}$ was applied to accelerate significantly the setting of a VMA modified mortar by compromising only slightly its printability (Kazemian et al. 2017). With regard to structural build-up a variety of accelerators were investigated for cementitious matrices with $0.15 \mathrm{wt} \%$ PCE and nanosilica (Yuan et al. 2020), whereby $\mathrm{Mg}\left(\mathrm{NO}_{3}\right)_{2}$ was identified as the most effective one. Comparing re-dispersible polymer powders based on polyvinyl acetate-ethylene (VAE) and polyvinyl acetate-vinyl versatate-ethylene showed an increase of the structural build-up rate for VAE with lower ethylene content (Zhang et al. 2020). Le et al. applied for high-performance fibrereinforced concrete with $1 \mathrm{wt} \%$ PCE $0.5 \mathrm{wt} \%$ retarder based on amino-tris(methylenephosphonic acid), citric acid and formaldehyde to meet optimized workability and printing time (Le et al. 2012a, b).

For fast setting sulphoaluminate cements (SAC), Chen et al. (2018b) conducted a study with response surface methodology and found a mix design with $0.3 \%$ HPMC, $0.3 \%$ PCE and $0.01 \% \mathrm{Li}_{2} \mathrm{CO}_{3}$ as the most suitable. For the same matrix system with similar HPMC- and PCEcontents, a prolongation of the setting time was achieved applying tartaric acid without compromising clearly the mechanical properties of 3D-printed specimen (Chen et al. 2018a). The reduction in the mechanical properties was more obvious using boric acid or sodium gluconate (Chen et al. 2020a). However, this could be compromised or even significantly improved by applying additional diatomite to the SAC pastes (Fig. 13).

Polymeric admixtures were also applied to strengthen the interlayer bond between 3D-printed filaments. Marchment et al. (2019) enhanced the interlayer bond strength of a 3D-printed mortar by applying cementitious pastes as a "glue" containing either a retarder, a VMA or a "PCE", and found mixtures with superplasticizer or retarder as the

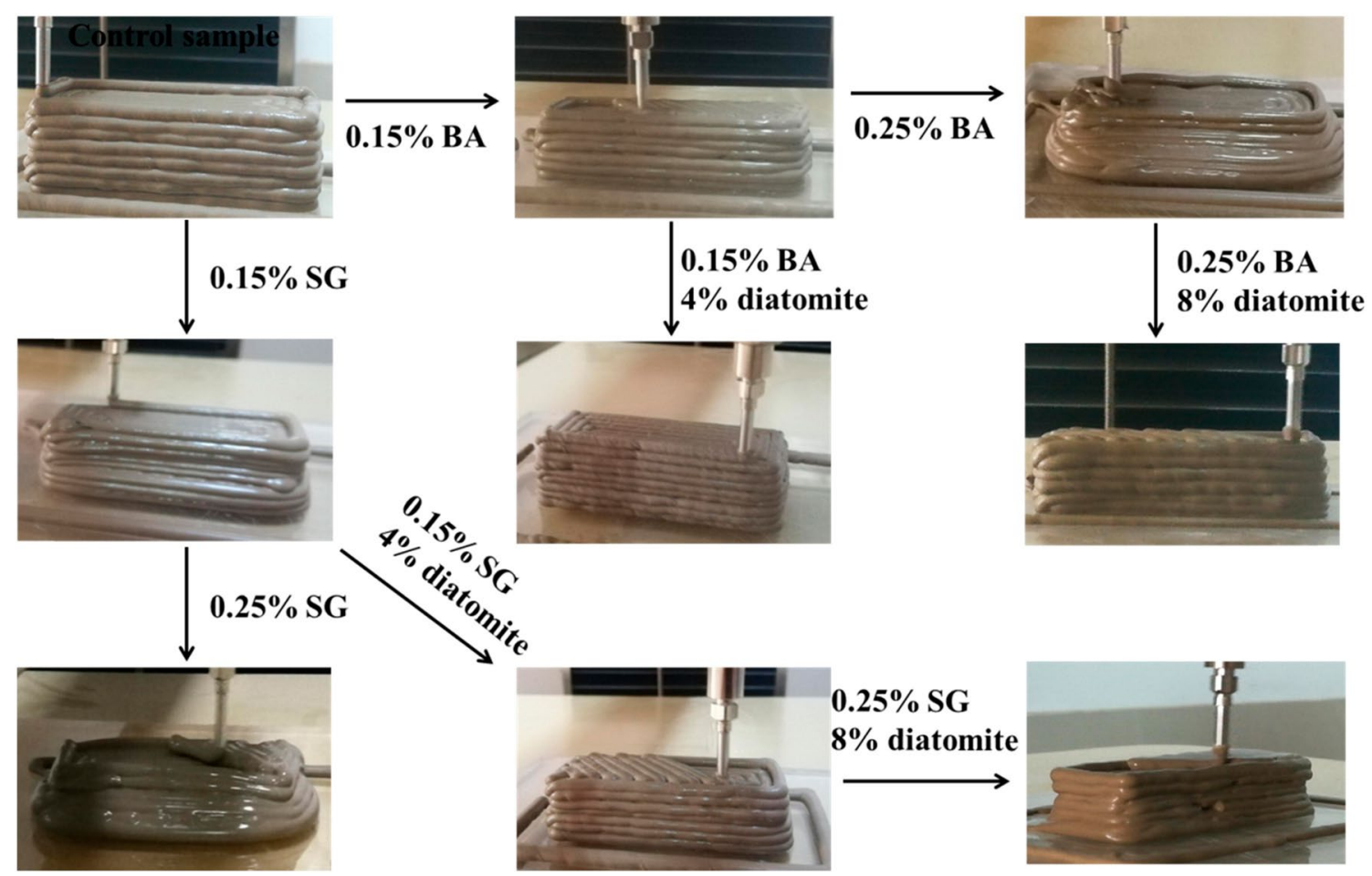

Fig. 13 3D-printed SAC pastes with different dosages of boric acid (BA), sodium gluconate (SG) and diatomite. Reprinted from Chen et al. (2020a), with permission of Elsevier, 2020 
most effective ones. Wang et al. (2020) investigated polymer-modified mortars as interlayer reinforcement materials and found a superior interlayer bonding for the epoxybased system compared to the chloroprene latex-mixtures.

However, for a deeper understanding of the abovedescribed effects one major challenge is the numerous and simultaneously applied admixtures. But for tailor-made additive manufacturing an understanding of their potential interactions is of high importance and should be envisaged for future research.

\section{Conclusions and future prospective}

This paper reviewed the developments towards nano-and micro-sized additives, including nanosilica, clay nanoparticles, graphene-based materials and chemical admixtures (i.e. viscosity modifying agents (VMAs) and superplasticizers (SP)) for additive manufacturing of cementitious composites. The overall conclusive statements are summarized in the following points:

- Nano additives act as a thickening agent, improving the thixotropic behaviour and the structural build-up of 3D-printed objects. The addition of nanosilica and clay nanoparticles increase the flocculation rate and improves the material's buildability. Both types of NMs are extremely effective in increasing the static yield stress as well as the rate of thixotropic build-up in the $3 \mathrm{D}$ printable composites.

- Nano-sized admixtures (nanosilica and nanoclays) are more effective in increasing the static yield stress as well as the rate of thixotropic build-up when compared to conventional micro-sized SCMs such as silica fume or metakolin.

- Significant improvement of early age compressive, flexural and interlayer bond strengths are reported in 3DPC containing NS or NC.

- When designing a 3DPC mixture the optimal dosage of NMs plays a vital role. Excessive dosage of NS and NC results in undesirable increment of specimen thixotropy resulting in difficulties in extrusion and weak interface between layers. This in turn might result in increased porosities as well as strength reduction.

- GBMs have demonstrated remarkable potential to enhance the fresh and hardened properties of both cement-based concretes and AAMs. The dosage-dependent nature of GMBs inclusion on the rheological behaviour of cementitious composite in the fresh state (i.e. the lubrication effect in specific dosages and the super water sorbent nature of these particles) requires an accurate mix design and optimisation.
- The particle size of the GBMs affects the dispersion of particles within the cementitious paste leading to an improved fresh and hardened property of the final objects. The reviewed investigations have concluded that the inclusion of small size GBM particles in AAMs is more promising in terms of compressive strength, elastic modulus, tensile strength, and fracture strain comparing to the addition of large-size particles.

- VMA are the most widely used polymeric admixtures for tailoring 3D printable cementitious materials. Their optimized dosages were mainly determined empirically and range up to $1 \mathrm{wt} \%$. Often they are used in combination with SP and accelerators. Their overlaying effects need to be clarified in near future for enabling a better understanding of their respective impacts.

Based on the presented studies, it can be concluded that despite comprehensive evaluations of the fresh properties printable composites modified with nanomaterials, the knowledge related to the hardened properties of the 3D printable composites is relatively limited. While, some of the data associated with the mechanical performances of cementitious composites are already available, the durability aspects of nano-modified mixtures are significantly limited. Therefore, further studies are required to understand the effects of nanoparticles on the engineering properties of 3D printable materials.

Acknowledgements This project has received funding from the European Union's Horizon 2020 research and innovation program under the Marie Skłodowska-Curie Grant agreement no. 841592.

Funding Open Access funding enabled and organized by Projekt DEAL.

\section{Declarations}

Conflict of interest On behalf of all authors, the corresponding author states that there is no conflict of interest.

Open Access This article is licensed under a Creative Commons Attribution 4.0 International License, which permits use, sharing, adaptation, distribution and reproduction in any medium or format, as long as you give appropriate credit to the original author(s) and the source, provide a link to the Creative Commons licence, and indicate if changes were made. The images or other third party material in this article are included in the article's Creative Commons licence, unless indicated otherwise in a credit line to the material. If material is not included in the article's Creative Commons licence and your intended use is not permitted by statutory regulation or exceeds the permitted use, you will need to obtain permission directly from the copyright holder. To view a copy of this licence, visit http://creativecommons.org/licenses/by/4.0/. 


\section{References}

Albar A, Chougan M, Al- Kheetan MJ, Swash MR, Ghaffar SH (2020) Effective extrusion based 3D printing system design for cementitious-based materials. Results Eng 6:100135. https://doi. org/10.1016/j.rineng.2020.100135

Alghamdi H, Nair SA, Neithalath N (2019) Insights into material design, extrusion rheology, and properties of 3D-printable alkaliactivated fly ash-based binders. Mater Des 167:107634. https:// doi.org/10.1016/j.matdes.2019.107634

Alkhateb H, Al-Ostaz A, Cheng AHD, Li X (2013) Materials genome for graphene-cement nanocomposites. J Nanomech Micromech 3:67-77. https://doi.org/10.1080/17470218.2016.1217246

Buswell RA, Leal de Silva WR, Jones SZ et al (2018) 3D printing using concrete extrusion: a roadmap for research. Cem Concr Res 2018(112):37-49. https://doi.org/10.1016/j.cemco nres.2018.05.006

Charitidis CA, Georgiou P, Koklioti MA, Trompeta A-F, Markakis V (2014) Manufacturing nanomaterials: from research to industry. Manuf Rev 1:11. https://doi.org/10.1051/mfreview/2014009

Chaves Figueiredo S, Çopuroğlu O, Schlangen E (2019a) Effect of viscosity modifier admixture on Portland cement paste hydration and microstructure. Constr Build Mater 212:818-840. https://doi. org/10.1016/j.conbuildmat.2019.04.020

Chaves Figueiredo S, Romero Rodríguez C, Ahmed ZY et al (2019b) An approach to develop printable strain hardening cementitious composites. Mater Des 169:107651. https://doi.org/10.1016/j. matdes.2019.107651

Chen M, Guo X, Zheng Y et al (2018a) Effect of tartaric acid on the printable, rheological and mechanical properties of 3D printing sulphoaluminate cement paste. Materials 11:2417. https://doi. org/10.3390/ma11122417

Chen M, Li L, Zheng Y et al (2018b) Rheological and mechanical properties of admixtures modified 3D printing sulphoaluminate cementitious materials. Constr Build Mater 189:601-611. https ://doi.org/10.1016/j.conbuildmat.2018.09.037

Chen Y, Chaves Figueiredo S, Yalçinkaya Ç et al (2019) The effect of viscosity-modifying admixture on the extrudability of limestone and calcined clay-based cementitious material for extrusion-based 3D concrete printing. Materials 12:1374. https://doi. org/10.3390/ma12091374

Chen M, Li L, Wang J et al (2020a) Rheological parameters and building time of 3D printing sulphoaluminate cement paste modified by retarder and diatomite. Constr Build Mater 234:117391. https ://doi.org/10.1016/j.conbuildmat.2019.117391

Chen Y, Chaves Figueiredo S, Li Z et al (2020b) Improving printability of limestone-calcined clay-based cementitious materials by using viscosity-modifying admixture. Cem Concr Res 132:106040. https://doi.org/10.1016/j.cemconres.2020.106040

Chen Y, Jansen K, Zhang H et al (2020c) Effect of printing parameters on interlayer bond strength of 3D printed limestone-calcined clay-based cementitious materials: an experimental and numerical study. Constr Build Mater 262:120094. https://doi. org/10.1016/j.conbuildmat.2020.120094

Chen Y, Romero Rodriguez C, Li Z et al (2020d) Effect of different grade levels of calcined clays on fresh and hardened properties of ternary-blended cementitious materials for 3D printing. Cem Concr Compos 114:103708. https://doi.org/10.1016/j.cemco ncomp. 2020.103708

Cheung J, Jeknavorian A, Roberts L, Silva D (2011) Impact of admixtures on the hydration kinetics of Portland cement. Cem Concr Res 41:1289-1309. https://doi.org/10.1016/j.cemco nres.2011.03.005

Cho S, Kruger J, van Rooyen A, Zeranka S, van Zijl G (2020) Rheology of 3D printable lightweight foam concrete incorporating nano-silica. In: Mechtcherine V, Khayat K, Secrieru E (eds) Rheology and processing of construction materials. Springer International Publishing, New York, pp 373-381. https://doi org/10.1007/978-3-030-22566-7_43

Chougan M, Marotta E, Lamastra FR, Vivio F, Montesperelli G, Ianniruberto U, Bianco A (2019) A systematic study on EN-998-2 premixed mortars modified with graphene-based materials. Constr Build Mater 227:116701. https://doi.org/10.1016/j.conbu ildmat.2019.116701

Chougan M, Hamidreza Ghaffar S, Jahanzat M, Albar A, Mujaddedi N, Swash R (2020a) The influence of nano-additives in strengthening mechanical performance of 3D printed multi-binder geopolymer composites. Constr Build Mater 250:118928. https:// doi.org/10.1016/j.conbuildmat.2020.118928

Chougan M, Marotta E, Lamastra FR, Vivio F, Montesperelli G, Ianniruberto U, Hamidreza S, Al-kheetan MJ, Bianco A (2020b) High performance cementitious nanocomposites: the effectiveness of nano-graphite (nG). Constr Build Mater 259:119687. https://doi.org/10.1016/j.conbuildmat.2020.119687

Douba A, Chan C, Berrios S, Kawashima S (2020) Synthesis of hybridized rheological modifiers for 3D concrete printing. In: Bos FP, Lucas SS, Wolfs RJM, Salet TAM (eds) Second RILEM international conference on concrete and digital fabrication. Springer International Publishing, Cham, pp 32-41. https://doi. org/10.1007/978-3-030-49916-7_4

Federowicz K, Kaszyńska M, Zieliński A, Hoffmann M (2020) Effect of curing methods on shrinkage development in 3d-printed concrete. Materials 13(11):2590. https://doi.org/10.3390/ ma13112590

Figueiredo SC, Rodríguez CR, Ahmed ZY, Bos DH, Xu Y, Salet TM et al (2019) An approach to develop printable strain hardening cementitious composites. Mater Des 169:107651. https://doi. org/10.1016/j.matdes.2019.107651

Gao X, Kawashima S, Liu X, Shah SP (2012) Influence of clays on the shrinkage and cracking tendency of SCC. Cem Concr Compos 34(4):478-485. https://doi.org/10.1016/j.cemconcomp .2012 .01 .002

García de Soto B, Agustí-Juan I, Hunhevicz J, Joss S, Graser K, Habert G, Adey BT (2018) Productivity of digital fabrication in construction: cost and time analysis of a robotically built wall. Autom Constr 92:297-311. https://doi.org/10.1016/j. autcon.2018.04.004

Ghaffar S, Mullett P (2018) Commentary: 3D printing set to transform the construction industry. Proc Inst Civil Eng Struct Build 171:737-738. https://doi.org/10.1680/jstbu.18.00136

Ghaffar SH, Corker J, Fan M (2018) Additive manufacturing technology and its implementation in construction as an eco-innovative solution Autom Constr 93:1-11. https://doi.org/10.1016/j. autcon.2018.05.005

Ghaffar SH, Corker J, Mullett P (2020) The potential for additive manufacturing to transform the construction industry. In: Sawhney A, Riley M, Irizarry J, Riley M (eds) Construction 4.0. Routledge, pp 155-187. https://doi.org/10.1201/97804 29398100-9

Graybeal, BA (2006). Material property characterization of ultrahigh performance concrete (no. FHWA-HRT-06-103). United States. Federal Highway Administration. Office of Infrastructure Research and Development.

Hamidi F, Aslani F (2019) Additive manufacturing of cementitious composites: materials, methods, potentials, and challenges. Constr Build Mater 218:582-609. https://doi.org/10.1016/j. conbuildmat.2019.05.140

Hoffmann M, Skibicki S, Pankratow P, Zieliński A, Pajor M, Techman M (2020) Automation in the construction of a 3D-printed concrete wall with the use of a lintel gripper. Materials 13(8):1800. https://doi.org/10.3390/ma13081800 
Horszczaruk E, Mijowska S, Mijowska E et al (2015) Nanocomposite of cement/graphene oxide-impact on hydration kinetics and Young's modulus. Constr Build Mater 78:234-242. https://doi. org/10.1016/j.conbuildmat.2014.12.009

Hou D, Lu Z, Li X, Ma H, Li Z (2017) Reactive molecular dynamics and experimental study of graphene-cement composites: structure, dynamics and reinforcement mechanisms. Carbon 115:188-208. https://doi.org/10.1016/j.carbon.2017.01.013

Ivanov LA, Xu LD, Bokova ES, Ishkov AD, Muminova SR (2020) Nanotechnologies: are view of inventions and utility models. Part V. Nano Constr 12(6):331-333. https://doi.org/10.15828 /2075-8545-2020-12-6-331-338

Jing G, Ye Z, Lu X, Hou P (2017) Effect of graphene nanoplatelets on hydration behaviour of Portland cement by thermal analysis. Adv Cem Res 29:63-70. https://doi.org/10.1680/jadcr 16.00087

Jo JH, Jo BW, Cho W et al (2020) Development of a 3D printer for concrete structures: laboratory testing of cementitious materials. Int J Concr Struct Mater 14:13. https://doi.org/10.1186/s4006 9-019-0388-2

Jolicoeur C, Simard M-A (1998) Chemical admixture-cement interactions: phenomenology and physico-chemical concepts. Cem Concr Compos 20:87-101. https://doi.org/10.1016/S0958 -9465(97)00062-0

Jolin M, Burns D, Bissonnette B, Gagnon F, Bolduc LS (2009). Understanding the pumpability of concrete. In: Proceedings of the 11th conference on shotcrete for underground support (Davos)

Jones W, Gibb A, Goodier C, Bust P, Song M, Jin J (2019) Nanomaterials in construction-what is being used, and where? Constr Mater 172(2):49-62. https://doi.org/10.1680/jcoma.16.00011

Kaszynska M, Zielinski A (2015) Effect of lightweight aggregate on minimising autogenous shrinkage in self-consolidating concrete. Procedia Eng 108:608-615. https://doi.org/10.1016/j.proen g.2015.06.186

Kazemian A, Yuan X, Cochran E, Khoshnevis B (2017) Cementitious materials for construction-scale 3D printing: laboratory testing of fresh printing mixture. Constr Build Mater 145:639-647. https ://doi.org/10.1016/j.conbuildmat.2017.04.015

Khan MA (2020) Mix suitable for concrete 3D printing: a review. Mater Today Proc. https://doi.org/10.1016/j.matpr.2020.03.825

Khan MS, Sanchez F, Zhou H (2020) 3-D printing of concrete: beyond horizons. Cem Concr Res 133:106070. https://doi.org/10.1016/j. cemconres.2020.106070

Krivenko P, Sanytsky M, Kropyvnytska T (2019) The effect of nanosilica on the early strength of alkali-activated Portland composite cements. Solid State Phenom 296:21-26. https://doi.org/10.4028/ www.scientific.net/SSP.296.21

Kruger J, Zeranka S, van Zijl G (2019b) An ab initio approach for thixotropy characterisation of (nanoparticle-infused) 3D printable concrete. Constr Build Mater 224:372-386. https://doi. org/10.1016/j.conbuildmat.2019.07.078

Kruger J, Van den Heever M, Cho S, Zeranka S, Van Zijl G (2019a) High-performance 3D printable concrete enhanced with nanomaterials. In: Proceedings of the international conference on sustainable materials, systems and structures (SMSS 2019), 20-22 March 2019-Rovinj, Croatia

Labonnote N, Rüther P (2017) Additive manufacturing: an opportunity for functional and sustainable constructions. In: challenges for technology innovation: an agenda for the future. Proceedings of the international conference on sustainable smart manufacturing. S2M 2016, pp 201-206. https://doi.org/10.1201/97813 15198101-41

Land G, Stephan D (2012) The influence of nano-silica on the hydration of ordinary Portland cement. J Mater Sci 47:1011-1017. https://doi.org/10.1007/s10853-011-5881-1
Le TT, Austin SA, Lim S, Buswell RA, Law R, Gibb AG, Thorpe T (2012) Hardened properties of high-performance printing concrete. Cem Concr Res 42:558-566. https://doi.org/10.1016/j. cemconres.2011.12.003

Le TT, Austin SA, Lim S, Buswell RA, Gibb AG, Thorpe T (2012) Mix design and fresh properties for high-performance printing concrete. Mater Struct 45:1221-1232. https://doi.org/10.1617/ s11527-012-9828-z

Lee H, Kim J, Moon J, Kim W, Seo E (2019) Correlation between pore characteristics and tensile bond strength of additive manufactured mortar using X-ray computed tomography. Constr Build Mater 226:712-720. https://doi.org/10.1016/j.conbuildmat.2019.07.161

Liu J, Yu C, Shu X, Ran Q, Yang Y (2019) Recent advance of chemical admixtures in concrete. Cem Concr Res 124:105834. https://doi. org/10.1016/j.cemconres.2019.105834

Lu B, Weng Y, Li M, Qian Y, Leong KF, Tan MJ, Qian S (2019) Systematical review of 3D printable cementitious materials. Constr Build Mater 207:477-490. https://doi.org/10.1016/j.conbuildma t.2019.02.144

Lv S, Ma Y, Qiu C, Zhou Q (2013) Regulation of GO on cement hydration crystals and its toughening effect. Mag Concr Res 65:12461254. https://doi.org/10.1680/macr.13.00190

Ma G, Wang L (2018) A critical review of preparation design and workability measurement of concrete material for largescale 3D printing. Front Struct Civ Eng 12:382-400. https://doi. org/10.1007/s11709-017-0430-x

Ma G, Wang L, Ju Y (2018) (2018) State-of-the-art of 3D printing technology of cementitious material-an emerging technique for construction. Sci China Technol Sci 61:475-495. https://doi. org/10.1007/s11431-016-9077-7

Malaeb Z, AlSakka F, Hamzeh F (2019) 3D concrete printing: machine design, mix proportioning, and mix comparison between different machine setups. In: 3D Concrete printing technology, pp 115-136. https://doi.org/10.1016/B978-0-12-815481-6.00006-3

Marchment T, Sanjayan J, Xia M (2019) Method of enhancing interlayer bond strength in construction scale 3D printing with mortar by effective bond area amplification. Mater Des. https://doi. org/10.1016/j.matdes.2019.107684

Marchon D, Kawashima S, Bessaies-Bey H et al (2018) Hydration and rheology control of concrete for digital fabrication: potential admixtures and cement chemistry. Cem Concr Res 112:96-110. https://doi.org/10.1016/j.cemconres.2018.05.014

Mechtcherine V, Nerella VN, Kasten K (2014) Testing pumpability of concrete using sliding pipe rheometer. Constr Build Mater 53:312-323. https://doi.org/10.1016/j.conbuildmat.2013.11.037

Mechtcherine V, Bos FP, Perrot A et al (2020) Extrusion-based additive manufacturing with cement-based materials_-production steps, processes, and their underlying physics: a review. Cem Concr Res 132:106037. https://doi.org/10.1016/j.cemconres.2020.106037

Mendoza Reales OA, Duda P, Silva E, Paiva M, Filho R (2019) Nanosilica particles as structural buildup agents for 3D printing with Portland cement pastes. Constr Build Mater 219:91-100. https ://doi.org/10.1016/j.conbuildmat.2019.05.174

Moeini MA, Hosseinpoor M, Yahia A (2020) Use of the chemical and mineral admixtures to tailor the rheology and the green strength of 3D printing cementitious mixtures. In: Bos FP, Lucas SS, Wolfs RJM, Salet TAM (eds) Second RILEM international conference on concrete and digital fabrication. Springer International Publishing, Cham, pp 73-82. https://doi.org/10.1007/978-3-03049916-7_8

Nerella VN, Hempel S, Mechtcherine V (2019) Effects of layer-interface properties on mechanical performance of concrete elements produced by extrusion-based 3D-printing. Constr Build Mater 205:586-601. https://doi.org/10.1016/j.conbuildmat.2019.01.235

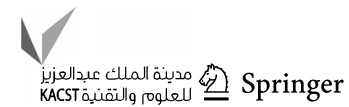


Neville AM, Brooks JJ (2010) Concrete technology. British Library, England

Pacewicz K, Sobotka A, Gołek $€$ (2018) Characteristic of materials for the $3 \mathrm{D}$ printed building constructions by additive printing. MATEC Web Conf 222:01013. https://doi.org/10.1051/matec conf/201822201013

Pan Z, He L, Qiu L, Korayem AH, Li G, Zhu JW, Collins F, Li D, Duan WH, Wang MC (2015) Mechanical properties and microstructure of a graphene oxide-cement composite. Cem Concr Compos 58:140-147. https://doi.org/10.1016/J.CEMCONCOMP .2015.02.001

Panda B, Unluer C, Tan MJ (2019) Extrusion and rheology characterization of geopolymer nanocomposites used in 3D printing. Compos Part B Eng 176:107290. https://doi.org/10.1016/j.compo sitesb.2019.107290

Panda B, Noor Mohamed NA, Paul SC et al (2019) The effect of material fresh properties and process parameters on buildability and interlayer adhesion of 3D printed concrete. Materials 12:2149. https://doi.org/10.3390/ma12132149

Panda B, Ruan S, Unluer C, Tan MJ (2019) Improving the 3D printability of high volume fly ash mixtures via the use of nano attapulgite clay. Compos Part B Eng 165:75-83. https://doi.org/10.1016/j. compositesb.2018.11.109

Panda B, Ruan S, Unluer C, Tan MJ (2020) Investigation of the properties of alkali-activated slag mixes involving the use of nanoclay and nucleation seeds for 3D printing. Compos Part B Eng 186:107826. https://doi.org/10.1016/j.compositesb.2020.107826

Papachristoforou M, Mitsopoulos V, Stefanidou M (2018) Evaluation of workability parameters in 3D printing concrete. Procedia Struct Integr 10:155-162. https://doi.org/10.1016/j.prost r.2018.09.023

Paul SC, Tay YWD, Panda B et al (2018) Fresh and hardened properties of 3D printable cementitious materials for building and construction. Arch Civ Mech Eng 18:311-319. https://doi. org/10.1016/j.acme.2017.02.008

Perrot A, Rangeard D, Nerella VN, Mechtcherine V (2018) Extrusion of cement-based materials-an overview. RILEM Tech Lett 3:91-97. https://doi.org/10.21809/rilemtechlett.2018.75

Prinsloo J, Sinha S, von Solms B (2019) A Review of Industry 4.0 manufacturing process security risks. Appl Sci 9(23):5105. https://doi.org/10.3390/app9235105

Qian Y, Ma S, Kawashima S, de Schutter G (2019) Rheological characterization of the viscoelastic solid-like properties of fresh cement pastes with nanoclay addition. Theor Appl Fract Mech 103:102262. https://doi.org/10.1016/j.tafmec.2019.102262

Quanji Z, Lomboy GR, Wang K (2014) Influence of nano-sized highly purified magnesium alumino silicate clay on thixotropic behavior of fresh cement pastes. Constr Build Mater 69:295300. https://doi.org/10.1016/j.conbuildmat.2014.07.050

Rahul AV, Santhanam M, Meena H, Ghani Z (2019a) 3D printable concrete: mixture design and test methods. Cem Concr Compos 97:13-23. https://doi.org/10.1016/j.cemconcomp.2018.12.014

Rahul AV, Santhanam M, Meena H et al (2019b) Mechanical characterization of 3D printable concrete. Constr Build Mater 227:116710. https://doi.org/10.1016/j.conbuildmat.2019.11671 0

Ranjbar N, Mehrali M, Alengaram UJ, Simon H, Metselaar C (2014) Compressive strength and microstructural analysis of fly ash/ palm oil fuel ash based geopolymer mortar under elevated temperatures. Constr Build Mater 65:114-121. https://doi. org/10.1016/j.conbuildmat.2014.04.064

Ranjbar N, Mehrali M, Mehrali M, Alengaram UJ, Zamin M (2015) Graphene nanoplatelet-fly ash based geopolymer composites. Cem Concr Res 76:222-231. https://doi.org/10.1016/j.cemco nres.2015.06.003
Reiter L, Wangler T, Roussel N, Flatt RJ (2018) The role of early age structural build-up in digital fabrication with concrete. Cem Concr Res 112:86-95. https://doi.org/10.1016/j.cemco nres.2018.05.011

Reiter L, Wangler T, Anton A, Flatt RJ (2020) Setting on demand for digital concrete - principles, measurements, chemistry, validation. Cem Concr Res 132:106047. https://doi.org/10.1016/j. cemconres.2020.106047

Rhee I, Lee JS, Kim YA, Kim JH, Kim JH (2016) Electrically conductive cement mortar: Incorporating rice husk-derived highsurface-area graphene. Constr Build Mater 125:632-642. https ://doi.org/10.1016/j.conbuildmat.2016.08.089

Roussel N (2018) Rheological requirements for printable concretes. Cem Concr Res 112:76-85. https://doi.org/10.1016/j.cemco nres.2018.04.005

Rubio M, Sonebi M, Amziane S (2017) 3D Printing of fibre cement-based materials: fresh and rheological performances, ICBBM2017. In: 2nd international conference on bio-based building materials. https://doi.org/10.26168/icbbm2017.74

Secrieru E, Fataei S, Schröfl C, Mechtcherine V (2017) Study on concrete pumpability combining different laboratory tools and linkage to rheology. Constr Build Mater 144:451-461. https://doi. org/10.1016/j.conbuildmat.2017.03.199

Shang Y, Zhang D, Yang C, Liu Y, Liu Y (2015) Effect of graphene oxide on the rheological properties of cement pastes. Constr Build Mater 96:20-28. https://doi.org/10.1016/j.conbuildma t.2015.07.181

Sharma S, Kothiyal NC (2015) Influence of graphene oxide as dispersed phase in cement mortar matrix in defining the crystal patterns of cement hydrates and its effect on mechanical, microstructural and crystallization properties. RSC Adv 5:5264252657. https://doi.org/10.1039/C5RA08078A

Sikora P, Abd Elrahman M, Stephan D (2018) The influence of nanomaterials on the thermal resistance of cement-based composites-a review. Nanomaterials 8(7):465. https://doi.org/10.3390/ nano8070465

Sikora P, Lootens D, Liard M, Stephan D (2020) The effects of seawater and nanosilica on the performance of blended cements and composites. Appl Nanosci. https://doi.org/10.1007/s1320 4-020-01328-8

Sikora P, Cendrowski K, Abd Elrahman M, Chung SY, Mijowska E, Stephan D (2020) The effects of seawater on the hydration, microstructure and strength development of Portland cement pastes incorporated with colloidal silica. Appl Nanosci 10:26272638. https://doi.org/10.1007/s13204-019-00993-8

Singh AP, Mishra M, Chandra A et al (2011) Graphene oxide/ferrofluid/cement composites for electromagnetic interference shielding application. Nanotechnology. https://doi.org/10.1088/09574484/22/46/465701

Skibicki S, Kaszyńska M, Wahib N et al (2020) Properties of composite modified with limestone powder for 3D concrete printing. In: Bos F, Lucas S, Wolfs R, Salet T (eds) Second RILEM international conference on concrete and digital fabrication. DC 2020. RILEM Bookseries, vol 28. Springer, Cham. https://doi.org/10.1007/9783-030-49916-7_13

Skoczylas K, Rucińska T (2018) Strength and durability of cement mortars containing nanosilica and waste glass fine aggregate. Cem Wapno Beton 23(3):206-215

Sobuz HR, Visintin P, Ali MM, Singh M, Griffith MC, Sheikh AH (2016) Manufacturing ultra-high performance concrete utilising conventional materials and production methods. Constr Build Mater 111:251-261. https://doi.org/10.1016/j.conbuildma t.2016.02.102

Soldano C, Mahmood A, Dujardin E (2010) Production, properties and potential of graphene. Carbon 48:2127-2150. https://doi. org/10.1016/j.carbon.2010.01.058 
Sonebi M, García-Taengua E, Hossain KMA, Khatib J, Lachemi M (2015) Effect of nanosilica addition on the fresh properties and shrinkage of mortars with fly ash and superplasticiser. Constr Build Mater 84:269-276. https://doi.org/10.1016/j.conbuildma t.2015.02.064

Tay YWD, Qian Y, Tan MJ (2019) Printability region for 3D concrete printing using slump and slump flow test. Compos Part B Eng 174:106968. https://doi.org/10.1016/j.compositesb.2019.106968

Valente M, Sibai A, Sambucci M (2019) Extrusion-based additive manufacturing of concrete products: revolutionizing and remodeling the construction industry. J Compos Sci 3:88. https://doi. org/10.3390/jcs3030088

Van der Putten J, Deprez M, Cnudde V, de Schutter G, van Tittelboom K (2019) Microstructural characterization of 3D printed cementitious materials. Materials (Basel). https://doi.org/10.3390/ma121 82993

Voigt T, Mbele JJ, Wang K, Shah SP (2010) Using fly ash, clay, and fibers for simultaneous improvement of concrete green strength and consolidatability for slip-form pavement. J Mater Civ Eng 22(2):196-206. https://doi.org/10.1061/ (ASCE)0899-1561(2010)22:2(196)

Wallevik OH, Feys D, Wallevik JE, Khayat KH (2015) Avoiding inaccurate interpretations of rheological measurements for cementbased materials. Cem Concr Res 78(A):100-109. https://doi. org/10.1016/j.cemconres.2015.05.003

Wang X, Wang K, Tanesi J, Ardani A (2014) Effects of nanomaterials on the hydration kinetics and rheology of Portland cement pastes. Adv Civ Eng Mat 3(2):142-159. https://doi.org/10.1520/ ACEM20140021

Wang L, Tian Z, Ma G, Zhang M (2020) Interlayer bonding improvement of 3D printed concrete with polymer modified mortar: experiments and molecular dynamics studies. Cem Concr Compos 110:103571. https://doi.org/10.1016/j.cemconcomp .2020 .103571

Wangler T, Roussel N, Bos FP et al (2019) Digital concrete: a review. Cem Concr Res 123:105780. https://doi.org/10.1016/j.cemco nres.2019.105780
Yuan Q, Zhou D, Huang H et al (2020) Structural build-up, hydration and strength development of cement-based materials with accelerators. Constr Build Mater 259:119775. https://doi. org/10.1016/j.conbuildmat.2020.119775

Zhang Y, Zhang Y, Liu G, Yang Y, Wu M, Pang B (2018) Fresh properties of a novel 3D printing concrete ink. Constr Build Mater 174:263-271. https://doi.org/10.1016/j.conbuildmat.2018.04.115

Zhang J, Wang J, Dong S et al (2019) A review of the current progress and application of 3D printed concrete. Compos Part A Appl Sci Manuf 125:105533. https://doi.org/10.1016/j.composites a.2019.105533

Zhang Y, Jiang Z, Zhu Y et al (2020) Effects of redispersible polymer powders on the structural build-up of 3D printing cement paste with and without hydroxypropyl methylcellulose. Constr Build Mater. https://doi.org/10.1016/j.conbuildmat.2020.120551

Zhong J, Zhou GX, He PG, Yang ZH, Jia DC (2017) 3D printing strong and conductive geo-polymer nanocomposite structures modified by graphene oxide. Carbon 117:421-426. https://doi. org/10.1016/j.carbon.2017.02.102

Zhou GX, Li C, Zhao Z, Qi YZ, Yang ZH, Jia DC, Zhong J, Zhou Y (2020) 3D printing geopolymer nanocomposites structure: graphene oxide size effects on a reactive matrix. Carbon 164:215 223. https://doi.org/10.1016/j.carbon.2020.02.021

Zhu C, Zhai J, Wen D, Dong S (2012) Graphene oxide/polypyrrole nanocomposites: one-step electrochemical doping, coating and synergistic effect for energy storage. J Mater Chem 22:63006306. https://doi.org/10.1039/c2jm16699b

Zhu B, Pan J, Nematollahi B et al (2019) Development of 3D printable engineered cementitious composites with ultra-high tensile ductility for digital construction. Mater Des 181:108088. https ://doi.org/10.1016/j.matdes.2019.108088

Publisher's Note Springer Nature remains neutral with regard to jurisdictional claims in published maps and institutional affiliations. 